Article

\title{
A Context Aware Smart Classroom Architecture for Smart Campuses
}

\author{
Li-Shing Huang ${ }^{1, * \mathbb{D}}$, Jui-Yuan $\mathrm{Su}^{2} \mathbb{D}$ and Tsang-Long Pao ${ }^{1}$ \\ 1 Department of Computer Science and Engineering, Tatung University, No.40, Sec. 3, Zhong Shan N. Rd., \\ Taipei City 104, Taiwan; tlpao@ttu.edu.tw \\ 2 Department of New Media and Communication Administration, Ming Chuan University, \\ 250 Zhong Shan N. Rd., Sec. 5, Taipei City 111, Taiwan; rysu@mail.mcu.edu.tw \\ * Correspondence: joeintw@gmail.com; Tel.: +886-2-28824564 (ext. 2599)
}

Received: 30 March 2019; Accepted: 29 April 2019; Published: 3 May 2019

\begin{abstract}
The Smart campus is a concept of an education institute using technologies, such as information systems, internet of things (IoT), and context-aware computing, to support learning, teaching, and administrative activities. Classrooms are important building blocks of a school campus. Therefore, a feasible architecture for building and running smart classrooms is essential for a smart campus. However, most studies related to the smart classroom are focused on studying or addressing particular technical or educational issues, such as networking, AI applications, lecture quality, and user responses to technology. In this study, an architecture for building and running context-aware smart classrooms is proposed. The proposed architecture consists of three parts including a prototype of a context-aware smart classroom, a model for technology integration, and supporting measures for the operation of smart classrooms in this architecture. The classroom prototype was designed based on our study results and a smart classroom project in Ming Chuan University (MCU). The integration model was a layered model uses Raspberry Pi in the bottom layer of the model to integrate underlying technologies and provide application interfaces to the higher layer applications for the ease of building context-aware smart classroom applications. As a result, application interfaces were implemented using Raspberry Pi based on the proposed technology integration model, and a context-aware energy-saving smart classroom application was implemented based on the proposed classroom prototype and the implemented web application interface. The result shows that, in terms of technology, the proposed architecture is feasible for building context-aware smart classrooms in smart campuses.
\end{abstract}

Keywords: smart classroom; smart campus; IoT; IoRT; Context-Aware; energy saving

\section{Introduction}

Classroom is a space for teaching and learning. A general classroom usually has a blackboard, a lectern, tables, and chairs. To make classroom activities more efficient, education institutes have been continuously deploying electronic products, such as microphone, projector, video camera, and computer, into classrooms during the last few decades. Today, a projection system connected to a computer with Internet access is already a basic requirement for classrooms in Taiwan. The next step for education institutes to enhance the functionality of classrooms shall be the introduction of the "Smart Classroom." With digital native students who are born and raised in an environment full of smart devices and multi-media, learning patterns of the current students need to be understood for developing suitable teaching methods. Like publishing and television network companies, institutes in the education service industry, including colleges and universities, need certain transformation to survive in this digital revolution era. Smart classroom can be a bridge to the future for education institutes. With smart classrooms, teaching methods and learning tools can be enhanced by current and emerging 
technologies. Researchers and teachers can evaluate teaching and learning performance with the data collected by facilities deployed in the smart classroom. Furthermore, smart classrooms are an important foundation of a smart campus. Smart campus is a concept of upgrading a campus environment in various aspects with emerging technologies. In Referece [1], 29 studies were reviewed to identify features, technologies, and applications of a smart campus. The authors state that elements such as internet of things (IoT), cloud computing, wireless network, mobile terminal, and radio-frequency identification (RFID) were essential parts in a smart campus. However, universities in different countries may focus on different smart campus topics. The Joint Information Systems Committee [2] (JISC) in the United Kingdom has released a research work focused on topics related to intelligent campus [3]. The key points of the concept of intelligent campus are: [3]

- The availability of connected devices and sensors

- The ability to collect, store, and process data

- An understanding of what the data is and how it can be used

- A set of goals to benefit the recipients in making use of the data

In Reference [4], a smart campus framework was proposed for African universities. Technologies elements in the proposed framework in Reference [4] are:

- Mobile and web applications;

- Intelligent systems and technologically advanced devices;

- Data analysis and decision Support;

- Storage and backup;

- Connectivity;

- Cyber security;

- Platforms.

In Reference [5], an energy conservation smart campus framework was proposed to develop an IoT-enabled energy conservation system for Covenant University and communities in Nigeria. In Reference [6], works related to the use of IoT devices in smart campus are discussed. Major smart campus applications, such as intelligent buildings, campus smart grids, learning environments, waste and water management, car parking and charging, and RFID access control were identified. In summary, the smart classroom is a concept related to utilizing information and communication technologies to produce a superior teaching and learning environment. Computing concepts such as sensor network, internet of things, context-aware computing, ubiquitous computing, pervasive computing, data mining and artificial intelligence are often mentioned while discussing topics about smart classroom. In addition to technical issues, studies related to smart classroom are often associated with education and school management issues.

In this work, we propose a context-aware smart classroom architecture for building and running smart classrooms in higher education institutes. The most significance part of this work is the proposed context-aware smart classroom architecture. The architecture is designed based on the results of the study presented in Section 1.1 and the ongoing smart campus project of Ming Chuan University in Taiwan. In the proposed architecture, essential elements of a context-aware smart classroom are defined based on our study results, including a novel technology integration model for building and managing multiple smart classrooms in the university campus, and supporting measures for physically implementing the model. In this work, the Raspberry Pi (RPi), a small and affordable computer for learning computer programming [7], is used as the major device for smart classroom control. Our study shows that architecture for massively building, maintaining, and integrating smart classrooms with a campus-wide view, a novel model, and learning based smart classrooms design has not appeared in previous studies.

As a result, the way of implementing each component of the proposed architecture are discussed in detail and are demonstrated with examples in this work. The remaining part of this study is organized 
as follows. The related works are reviewed in the following subsections of this section. The components of the proposed architecture, including a context-aware smart classroom prototype, a technology integration model, and the supporting measures for smart classroom operations, are described in Section 2. The implementations to prove the concepts of the proposed architecture are demonstrated in Section 3. Discussions and conclusions are given in Section 4.

\subsection{Background and Related Works}

Studies related to this study are reviewed in this section. Studies related to different topics, including classroom environment, context-aware, energy issues, and Ming Chuan University (MCU) Smart Classroom Project, are reviewed in the following four subsections respectively.

\subsubsection{Physical Environment and Smart Classrooms}

Some research works focus on taking a smart classroom as a tool to measure lecture quality. In [8], authors use sensors to retrieve features, such as noise level, $\mathrm{CO}_{2}$ level, temperature, humidity, lecturers' voice, and lecturers' motion, in smart classrooms. Collected data are evaluated by various classification algorithms. The result shows that $\mathrm{CO}_{2}$ level, temperature, humidity, and noise level are the main environmental factors that affect lecture quality. The relationship between physical environment and students' focus during lectures was analyzed in [9]. The level of $\mathrm{CO}_{2}$, temperature, air pressure, humidity, noise, and lecturer's voice were collected with IoT devices. The analysis shows that the level of $\mathrm{CO}_{2}$, the average value of the absolute deviations of the received noise, and the combination of temperature and humidity have a significant impact on students' focus. In Reference [10], the relationship between students' perceived effectiveness of educational technologies, learning motivation, participation, and learning outcome was discussed. The analysis shows that, in the smart classroom, the relationship between students' learning outcome and participation was positive while motivation and perceived effectiveness of technologies were not related to students' learning outcome. Responses from students related to cold temperature, seat number, classroom location, chair design, relaxing atmosphere reflected that physical environment was an important factor to be considered in smart classroom design [10]. In Reference [11], history changes in classroom design were reviewed and various kinds of new classroom design projects in higher education institutes in the US, such as Student-Centered Active Learning Environment for Undergraduate Programs (SCALE-UP) of the North Carolina State University, Technology Enabled Active Learning (TEAL) of the Massachusetts Institute of Technology, Active Learning Classrooms (ALC) of the University of Minnesota, were also reviewed. Questionnaire surveys about the effects of ALC were conducted in Reference [11]. The result shows that in traditional classroom seating positions discriminate students' learning experiences, and ALC did not produce positional discrimination. In Reference [12], a web survey about the Future Classroom Lab (FCL) [13] by European Schoolnet [14] was applied. Learning zones [15], such as interact, present, develop, investigate, create, and exchange, were designed in FCLs for different kinds of goals. The result shows that the physical space of the FCL is perceived as positive. In Reference [16], a teaching model based on smart classroom for financial accounting courses was proposed. Five dimensions, including showing, manageable, accessible, real-time interactive, and testing, of smart classrooms are summarized. Environment factors, such as air, sound, color, smell, light, temperature, humidity, attendance, monitoring, were also summarized in Reference [16].

As a summary, classroom design, such as seat arrangement, and environmental factors, such as $\mathrm{CO}_{2}$ level and temperature, were related to teaching and learning quality. Therefore, classroom seat design and environment factors were taken as essential elements of the proposed smart classroom architecture.

\subsubsection{Technologies in Smart Classrooms}

Software, models, and architectures have been proposed or used in previous studies to address smart classrooms related issues. In Reference [17], a multi-agent software framework called "The Open Agent Architecture (OAA)" [18] was used to build a classroom with two smart on-wall interactive 
boards for tele-education. In Referece [19], an infrastructure named "Smart Platform" was proposed to resolve communication issues between agents for tele-education application. In Referece [20] a system named "Network Education Ware (NEW)" [21] was proposed to address network bandwidth issues by adopting open source software applications. In Reference [22], a middleware named CAMPS was proposed. For addressing context-aware issues for distance learning and key factors of a smart classroom, such as user, location, time, activity, service, environment, and platform, are defined in the context structure of [22]. In Reference [23], a synchronized distance learning system named "Open Smart Classroom" was proposed and web service technology is used for providing functions such as remote software control, file upload, and adding new remote classrooms, including mobile devices, to a synchronize live course.

Important technical features in different types of smart classrooms are also discussed in previous studies. In Reference [24], key factors of a smart classroom, such as voice recognition, computer vision, software for remote students, interactive media board, voice recognition, computer vision, live video, and pervasive computing, are clearly stated. The Radio-frequency identification (RFID) is wildly used in various kinds of applications such as door security, personnel management, transportations, and digital wallets. In Reference [25], the authors developed a smart classroom system based on near-field communication (NFC), which is a variation of RFID. The proposed system is used to perform student attendance management function and real-time interactive function, the result shows that the interactive functions have positive impacts on students' learning attitudes. Interactive whiteboard technology (IWBT) is an important feature in smart classrooms. In Refrence [26], studies related to the effect of using IWBT and user responses are reviewed. The result shows that IWBT is an appropriate teaching tool in certain conditions. Advantages and disadvantages of IWBT are also described in Reference [26], Technical problems and misconfigurations of hardware can be a major reason for user dissatisfaction. In Reference [27], authors state that large projected displays have good impacts on student groups' internal interactions and collaborations and help teachers to observe the state of the whole class. In Reference [28], the learning outcome of technology-rich classrooms and multi-media classrooms is analyzed. As a result, wireless display and shared screens for students in the classroom are crucial for sharing learning outcomes and promoting interaction. And in Reference [29], authors state that digital natives are reliant on using graphics for communication. Although teachers may not feel comfortable with cameras and video-recording devices [26], these devices are necessary for distance learning, course content producing, and presentation live streaming. In Reference [30], a survey on role of IoT in education, items such as interactive whiteboards, tablets and mobile devices, 3-D printers, eBooks, student ID cards, temperature sensors, security cameras, electric lighting, attendance tracking systems and wireless door locks, are listed as common IoT devices in smart classroom. Challenges for integrating IoT and education, such as security and privacy, reliable Wi-Fi connection, management issues, and cost are also stated in Reference [28]. In Reference [31], a case of using augmented reality in smart classroom was discussed. The result shows that criteria of motivation, learning curve, and memorization of the students in the experimental team are improved. In Reference [32], a system for giving in-class presenter real-time suggestions to improve the quality of the presentation based on deep learning-based emotion recognition was proposed. The proposed system in Reference [32] demonstrates a novel smart classroom application. However, the application needs lots of computation resource. Thus, a backend high-performance cloud service is needed for this application. In Reference [33], a framework is proposed to perform learning analytics tasks in a smart classroom. The communications between components are based on Simple Object Access Protocol (SOAP) Web Services. Web services can be registered, discovered, and invoked by agents. A middleware named AmICL (Ambient Intelligence and Cloud Learning), is used for objects in the smart classroom to adjust behavior according to the context, and the requirements of the users. The learning analytic example in Reference [33] demonstrates the process of recognizing students, supervise learning process, apply analytic tasks, recommend learning resources, identify communities of students, reinforce concepts with AR technology, predict learning performance, and evaluate the quality of learning resources. 
In Reference [34], a model for solving the performance issue of location-aware application in smart classrooms is proposed. In Reference [35], a storage management system is proposed to improve energy consumption and performance in smart classroom multi-media applications.

In Reference [36], Preference Instrument of Smart Classroom Learning Environments (PI-SCLE) is proposed for understanding students' preferences toward the smart classroom. According to the instrument documentation of Reference [36], communication with others, idea sharing, enough workspace, classroom atmosphere, flexible furniture arrangements, interactive visual displays, multiple small group discussions, wireless connectivity, user-friendly learning tools, present learning topics in various ways, share contents with digital devices, face-to-face digital instruction, are topics that should be considered while building a smart classroom. As a summary, smart classrooms may be used as a tool or target to do education-related study, technology-related factors are positive for learning outcome, and technology problems may cause user dissatisfaction. Therefore, technologies matters to learning activities and the ways for building, integrating, and maintaining a massive amount of smart classrooms are included in the proposed architecture.

Technologies and devices used in this work, including Raspberry Pi, Python, Flask, PHP, MariaDB, RFID, RS232, and RS485 are briefly addressed as follows:

- $\quad$ Raspberry Pi [7]: Raspberry Pi Foundation, which is a UK-based charity, starts to build a series of low-cost, high-performance palm-size computer boards for teaching computer-related subjects since 2012. Raspberry Pi single board computers become very popular because of its price, quality, compatibility, documentation, and community support. In our proposed model, Raspberry Pi is used to integrate hardware devices, which have various kinds of interfaces, and provide web application interfaces for high-level applications.

- Python [37]: Python is a very popular general purpose computer programming language. The official operating system of Raspberry Pi provides a built-in python development environment, and official documents of Raspberry Pi provide a massive amount of example of using Python to get things done. Therefore, Python is used in this work to develop device control procedures and web application interfaces on Raspberry Pi boards.

- Flask [38]: Flask is one of the most popular Python web application frameworks. With Flask, which is a lightweight framework, things are simple, and developers can start to build web applications without installing many packages and configuration. Therefore, prototype implementation and proof of concepts can be done quickly, and researchers start to use Flask in research projects [39-47] in recent years. In this study, we use Flask as the web framework to build web application interfaces in Python on Raspberry Pi computers.

- PHP [48]: PHP, which stands for PHP: Hypertext Preprocessor, is one of the most popular general-purpose scripting languages for server-side web application development. PHP is capable of processing heavy-duty web transactions, and according to [49], many important websites, such as Facebook, Wikipedia, Yahoo, and WordPress, are using PHP as the major back-end web technology. In this study, PHP is used in the central web server to build applications on top of the web application interfaces provided by the Raspberry Pi computers, which are located in smart classrooms.

- MariaDB [50]: MariaDB is one of the most popular open-source relational database management system (RDBMS) in the world. It's forked from MySQL [51] and guaranteed to stay open source. MariaDB intends to maintain high compatibility with MySQL. Therefore, a large number of PHP web applications can switch the back-end database from MySQL to MariaDB without much code modification. In this study, MariaDB is installed on the central web server and used as the back-end database to support PHP web applications.

- RFID: RFID is a wireless communication technology that uses radio frequency (RF) waves to transfer identifying information between tagged objects and readers without line of sight. Passive RFID can track products in supply chains from the supplier to the distribution center, warehouse, and point of sale [52]. Radio-frequency identification (RFID) has become one of 
the most widely used technologies in the world, and our life is full of RFID application, such as small payments, transportation, car access control, and door access control. In this study, RFID tag is used as the identification card in the door access control application.

- RS232 and RS485: RS232 and RS485 are standards defining the electrical characteristics in serial communications systems. The RS-232 standard had been commonly used in computer serial ports for connections to peripheral devices, such as modems, printers, computer mice, uninterruptible power supplies. RS485 can be used effectively over long distances and in electrically noisy environments. Multiple receivers may be connected to such a network in a linear, multidrop bus. Therefore, RS485 is often used in industrial control systems [53,54]. In smart place applications, most commercial controllable devices are providing control functions through RS485 and RS232.

In smart classrooms, devices such as air conditioner, projector, HDMI switch, and scrollable projector screen need to be controlled through RS485, RS232, and other interfaces. A good method is needed for handling the chaos situation when various kinds of devices with various kinds of control interfaces are installed in hundreds of classrooms. However, the studies related to smart classrooms reviewed in this sub-section are mostly focused on addressing or discussing particular education or technology issues. Therefore, the proposed architecture is essential. A general smart classroom requirement is clearly defined in the proposed smart classroom prototype, a layered technology integration model, and support measures are proposed to minimize development and management effort. With the proposed technology integration model, Raspberry Pi computers are used to connect to devices with RS232 or RS485 directly in smart classrooms. Procedures to control those devices are defined as Layer 1 device actions. The Layer 1 actions are implemented on Raspberry Pi computers and are packed as Layer 2 basic operations, using Python and Flask, in forms of web application interfaces. Therefore, with smart classrooms having different brand or model of the devices installed, developers only need to implement Layer 1 device control procedures for different devices and build corresponding Layer 2 basic operations. Procedures in Layer3 can launch Layer 2 smart classroom operations of different smart classrooms, which may have different kinds of devices installed, with unified command format.

\subsubsection{Context-Aware and Energy Saving Related Studies}

In Reference [55], important features about ambient intelligent computing including embedding, personalized, adaptive, anticipatory are stated. Key factors in a smart learning environment, such as context awareness, natural user interaction, seamless learning across contexts, collaborative learning, are also stated. Technology factors such as GPS, location sensor, and RFID applications are also described in Reference [55]. In Reference [56], a framework is proposed for smart city applications. Three layers, including and IoT layer, a Fog layer, and a Cloud layer, are defined in the proposed framework. IoT related applications are categorized into three types, which are IoT based application, IoT and smartphone-based application, and smartphone as IoT based application. The proposed framework uses three steps, including data collection, data preprocessing, and data processing and analytics to manage the collected data. Two smart classroom related applications are implemented based on Arduino [57]. As a summary, context awareness is an important factor for a classroom to be "Smart." Therefore, some factors related to context awareness will be included in the proposed architecture.

In Reference [58], many energy operation models related to smart city are reviewed and classified into five intervention areas: generation, storage, infrastructure, facilities, and transport. The authors state that optimized operation and management can save $20 \%$ to $30 \%$ energy consumption of a building without changing the structure or hardware configuration of the system. The authors also state that a building must be an active participant in the power system, instead of being a passive and unresponsive energy consumer, to achieve the desired energy objectives. In Reference [59], a hierarchical decision-making strategy for the energy management of a smart city was proposed to identify an optimal set of action plans for urban areas. The result shows that the proposed strategy in 
Reference [59] can improve city energy performances, by the given budget constraint, and deal with complex problems including conflicting objectives and requirements, fragmented decision making, and subsystem cross optimization. Some studies, such as References [60-62] are focused on addressing issues related to district-level energy systems. In Reference [60], a multicommodity energy management system was proposed to address flexibility and scalability issues with decentralized resource allocation and load scheduling methods. The simulation result shows that the decentralized algorithm in Reference [60] had similar performances compared to the centralized approach so improvements in the usage of locally generated energy can be achieved. In Reference [61], a decentralized resource allocation approach for sharing renewable energy among interconnected smart homes is proposed. The simulation result shows that the proposed approach exploits the potential of renewable energy source sharing. Therefore, the cost of individual user energy consumption can be reduced. In Reference [62], an energy management was proposed to aggregate energy prosumers in an energy district which has demand response availability. The simulation result shows that the proposed scheme can reduce the reverse energy flow at night and reduce peak power in daytime hours in energy districts. Some studies, such as [63-65] were focused on developing methods to optimize energy management in building or home level. In Referece [63], a distributed optimization algorithm for scheduling the energy activities in a microgrid was proposed. The users in the microgrid have individually controllable loads, a common energy storage system, and a shared renewable energy source. The result shows that, with the proposed algorithm, energy consumption costs can be reduced by sharing energy storage. In Reference [64], an energy management platform for intelligent buildings was developed. The platform was developed based on a commercial supervisory control and data acquisition (SCADA) system from Siemens. The SCADA system used in Reference [64] can integrate different technologies in modern buildings. A predictive controller and a communication channel to the SCADA system are implemented. Simulation and experimental result shows that the proposed platform optimizes the satisfaction of user explicit preferences, subjected to the constraints of energy waste minimization. In Reference [65], a scheduling technique is proposed to manage electrical activities in a smart home, which has controllable home appliances, storage devices, and energy generators, for minimizing energy cost. Energy is produced from renewable and dispatchable sources. The simulation result shows that the proposed approach in Reference [65] can exploit the local energy generation and storage. Therefore, energy consumption costs can be reduced while complying with customer energy needs.

In Reference [66], the energy efficiency of cyclic downtime control methods were evaluated, and authors state that the best energy-saving efficiency was achieved by the mode of cycling turning air conditioning units on for $15 \mathrm{~min}$ and off for $5 \mathrm{~min}$. In Reference [67], a field survey for energy consumption in university building was conducted in Korea. Factors including space usage, construction year, orientation, shape factor, window area, shading devices, heating equipment, cooling equipment, and lighting system were used as parameters to analyze potential energy consumption characteristics of different buildings. Automatic standby power cutoff switches, reduction of power for lightings, adjustment of indoor air temperature are selected as energy-saving strategies in Reference [67]. In Reference [67], the authors use automatic standby power cutoff switches to reduce $10 \%$ plug load in energy-guzzling buildings. Authors also suggest that changing occupants' behavior can reduce building energy usage. In Reference [68], the authors state that the major electricity used in the educational buildings was the lighting system, which consumes almost $42 \%$ of total energy. In Reference [69], authors also state that light in classrooms is a significant portion of the energy consumption is post-secondary education institutes. To discover the most common patterns in lighting waste, a methodology based on data mining was proposed in Reference [69], the result shows that the lights were turned on with no one in the monitored classroom for $10.6 \mathrm{~h}$ in an average day. The authors of Reference [69] mentioned that occupancy-based lighting control systems, which are based on turning the lights off when a state of no occupancy is detected in the monitored space, 
which is effective for reducing lighting energy waste. However, when the class schedule is dynamically changing, the energy saving rules predefined based on a fixed schedule is no longer useful.

As a summary, lots of energy has been wasted in classrooms and energy waste in classrooms can be greatly improved by correctly turning off unnecessary devices. Therefore, ways to save energy in smart classroom are also included in the proposed architecture.

\subsubsection{The MCU Smart Classroom Project}

Ming Chuan University (MCU) [70] is an international university in North Taiwan. All classrooms in MCU were turned into technology-rich classrooms before 2005. Every classroom in MCU has at least one television connected to an internal closed circuit television (CCTV) system, a high-resolution projector connected to a computer with an Internet connection, and a sound system with audio mixer for sounds from microphone and the computer, and a security camera. The devices in classrooms are controlled by software and hardware developed by MCU. In 2017 MCU starts a plan to start upgrading the whole campus to smart campus with emerging technologies. The MCU Smart Classroom project is a subproject of the smart campus plan. As a result, the first smart classroom construction in this project is completed in spring 2018. Ming Chuan University has about 300 classrooms in Taipei and Taoyuan campus; the number of occupants in a classroom is usually between 60 to 80 . The MCU Smart Classroom project is still ongoing, and the outcomes of this project are not published. Therefore, we review the smart classroom design of this project in this sub-subsection to cite the outcome of the MCU Smart Classroom project as an important foundation of this study. Essential devices, features and functions of the smart classrooms in MCU are listed as follows:

- A 1080P laser projector

- Two large touch interactive boards

- Projector and interactive boards have wireless display capability for mobile devices

- Touch screen for the teacher computer

- RFID based Door access control

- A Wall mount digital information board for dynamic classroom schedule and other applications

- An AI service chatbot in the digital information board

- Almost all devices in this classroom can be controlled by a computer program

- Sensors for collecting environment parameters

- Environment parameters are monitored, and devices' operations in this classroom will be triggered by certain environment parameters

- All chairs for students are swivel tablet chairs for different types of lecturing and group discussion.

- All light sets can be controlled individually

- Several predefined classroom modes, which are combinations of control actions to lights, projector, projector screen, and interactive boards, are provided for users to control multiple classroom devices in one click for different classroom scenarios

- All the devices can be controlled in this classroom can be controlled by teachers computer and mobile phone

- Predefined classroom modes can be triggered by voice and classroom schedule

Smart classrooms provide convenient functions and advanced features to support teaching and learning activities. A smart classroom contains many devices. A simple device control operation may related to control various kinds of technologies. Therefore, when a school-wide smart campus plan is ongoing, and many technology-rich classrooms are about to be upgraded to the smart classroom, an architecture for integrating various kinds of underlying technologies is needed in terms of technology, cost, and resource administration. 


\subsubsection{IoT, Fog and Cloud Computing}

According to Reference [71], Internet of Things (IoT) is an infrastructure enabling advanced service by interconnecting physical and virtual things based on information and communication technologies. Internet of Things devices are one of the key elements to give an environment computation ability such as context awareness. A smart classroom is a classroom with many IoT devices. With IoT device, actions such as sensing, actuation, and data capture can be performed in smart places. Internet of Things devices are often designed to cooperate with cloud services. Cloud computing is a model for enabling ubiquitous, convenient, on-demand network access to a shared pool of configurable computing resources [72]. With cloud services, smart places can perform complex computation, such as facial recognition applications, without installing high-performance computing resources in every smart place. In Reference [73], definitions and trends of IoT are clearly stated, and IoT elements such as Radio Frequency Identification (RFID), Wireless Sensor Networks (WSN), addressing schemes, data storage, data analytics, and visualization are reviewed. IoT applications including personal, home, enterprise, utilities, and mobile are also discussed. A cloud platform named Aneka is used to demonstrated cloud resource provisioning and data analytics for IoT applications. Finally, challenges such as architecture, energy efficient sensing, secure reprogrammable networks and privacy, quality of service, new protocols, participatory sensing, data mining, GIS-based visualization, cloud computing, and international activities are discussed in Reference [73]. Cloud-based IoT systems often encounter issues such as scale, heterogeneity, latency, and security. These issues can be improved or addressed by adding a layer between the IoT network and cloud services. Fog computing is a computing model to address cloud-IoT issues [74]. In References [75], fog computing and IoT scenarios, such as connected vehicle, smart grid, sensors, and actuators, are discussed. In Reference [76], the author reported that fog computing is needed for companies in different industries to handle the computation issues between IoT network and cloud network. In Reference [77], a smart e-Health Gateway is proposed to bring intelligence to IoT-based healthcare systems. In Reference [78], a fog computing-based solution is proposed based on Reference [77] by enhancing IoT-based healthcare applications in terms of energy efficiency, performance, reliability, and interoperability. In our proposed architecture, IoT devices are important building blocks of the proposed context-aware smart classrooms prototype, and the proposed technology integration model is similar to the Fog computing model. With our proposed model, different kinds of IoT devices and cloud computing resource and be easily linked to form new smart classroom applications.

\subsubsection{Smart Campus}

In Reference [79], a smart campus sensor system was developed at the University of Glasgow in the United Kingdom. The authored use Raspberry Pi to build sensor nodes called supersensors, which are directly connected to multiple sensors and responsible for retrieving and transmitting sensor data. The supersensors also behave autonomously to perform tasks such as dynamic reconfiguration and communicating with other local devices. A microservice architecture as also proposed in Reference [79], and a room temperature monitoring application based on the proposed architecture was also demonstrated in Referenece [79]. In Reference [80], a smart campus IoT framework was proposed to address issues related to energy consumption, classroom functionality, safety, and cybersecurity, and machine-learning algorithms were employed in the proposed framework. In reference [81], an Android-based school information system was made. The system provides functions such as notifications, location service, emergency contact list, temperature monitoring, and water tank monitoring. In Reference [82], a fast-paced development experience of a smart campus IoT platform was presented. Raspberry Pi, Arduino, sensor modules, and commercial all-in-one sensor devices were used in the platform. Raspberry Pi was used as a hub device, which is a bridge between sensor devices and cloud services. The authors of Reference [82] state that even students with no prior IoT knowledge could build a generic IoT platform within a short period. In Reference [83], the demand for a smart campus online teaching platform under the background of the $5 \mathrm{G}$ network was analyzed, and an online teaching platform based on the four initiatives operation 
model was illustrated. In Referene [84], a smart campus service discovery algorithm on the situational awareness system framework for smart campus was proposed. The authors of Reference [84] state that the smart campus platform based on situational awareness can efficiently fuse perceptual data and can make corresponding predictions of various behaviors.

\section{Our Proposed Context-Aware Smart Classroom Architecture}

The proposed architecture in this study contained three parts including a general smart classroom prototype, a technology integration model and supporting measures for the integration model, and daily operations of smart classrooms. The smart classroom prototype was designed based on our study and the MCU Smart Classroom project. The technology integration model was a model to integrate different technologies in a smart classroom for providing a unified structure to access underlying devices in smart classrooms. The supporting measures, in terms of technology, are concepts and rules necessary for smart classroom operations of the proposed model.

\subsection{The Context-Aware Smart Classroom Prototype}

In this subsection, a context-aware smart classroom prototype is proposed and discussed. The prototype evolved from classroom types in the sequence of technology-rich classroom, smart classroom, and smart classroom with context awareness. Features and functions of the prototype classroom are described in the three sub-subsections, respectively. Since a large part of the proposed prototype was based on the MCU Smart Classroom project. We use pictures taken from one of the MCU Smart Classrooms to illustrate the concepts of the classroom prototype. In the pictures, the portions link to the listed concepts in the prototype will be marked with white labels.

\subsubsection{Basic Requirements of a Technology-Rich Classroom}

A smart classroom is a technology-rich classroom to support classroom activities, including lecturing, group discussion, presentation, and tele-education, with technology devices. The requirements to build a basic technology-rich classroom are listed as follows:

1. Basic requirements for a comfortable teaching and learning environment, as shown in Figures 1 and 3.

- Whiteboards or blackboards for traditional lecturing.

- A lectern or a table for teacher.

- Swivel tablet chairs for different lecture style.

- Fans for air circulation.

- Air conditioner for temperature control.

- Lights should be divided into several sets with independent power switch.

2. Basic requirements for teaching with digital lecture material, as shown in Figure 2.

- A general purpose personal computer with popular operating system and software applications installed and Internet connectivity.

- The computer is connected to at least two displays. One for controlling the computer, the other is a large screen for all audience.

- The computer controlling display should have the multi-touch function for teachers to put marks with fingers on the displayed contents during a lecture.

- Microphone for lecturing or presentation.

- An audio speaker which takes both the computer's audio and microphone as a sound input source.

- Video/audio switches for devices such as a notebook computer or DVD player. 


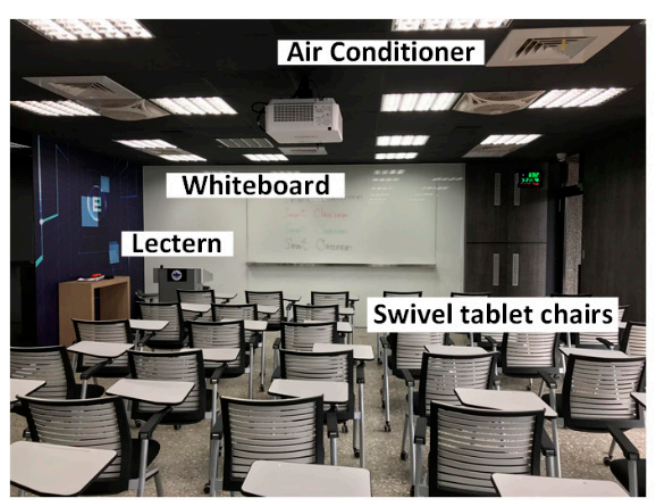

(a)

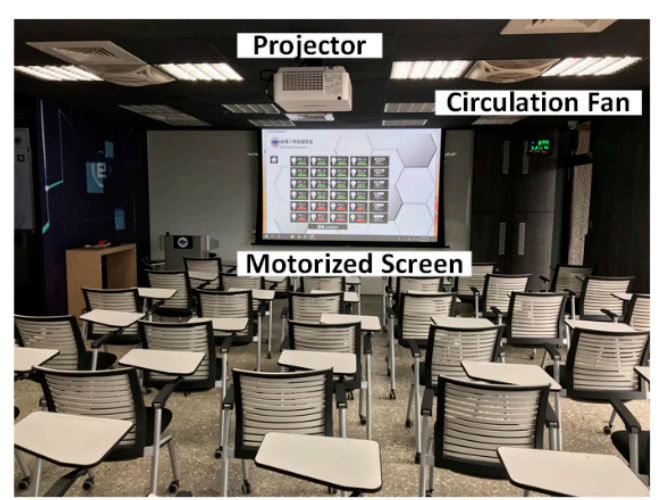

(b)

Figure 1. Basic requirements for a comfortable teaching and learning environment: Lights in different areas can be controlled respectively; (a) a whiteboard for traditional lecture. Chairs with wheels and a tablet for the convenience of notes taking, using a notebook computer, and group discussion, A lectern for teacher with a computer connected to a touch screen and the projector; (b) a projector with motorized screen for lecturing with digital contents. Circulation fans and air conditioner for a comfortable learning environment. Lights in different areas can be controlled respectively.

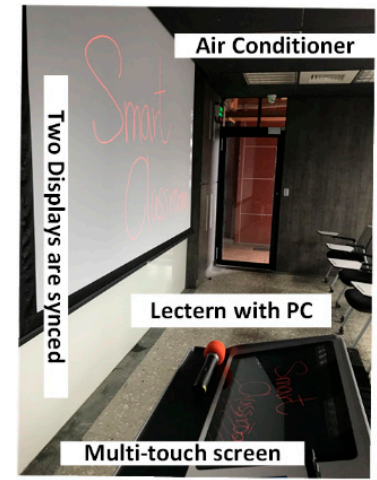

(a)

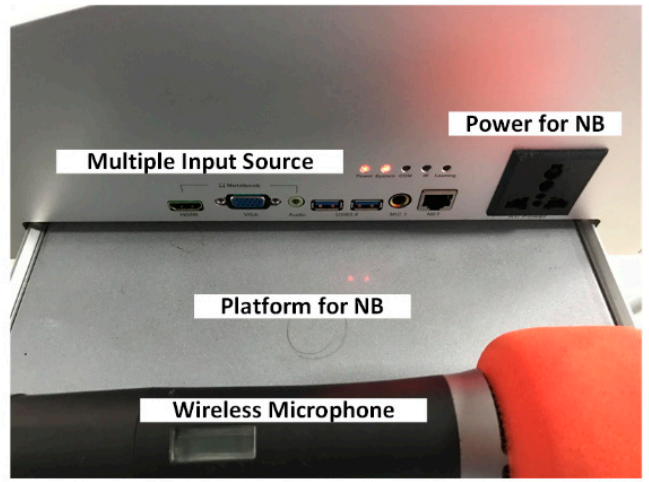

(b)

Figure 2. Basic requirements for teaching with digital lecture material: (a) A computer installed in the lectern connected to the projector and a multi-touch screen, the input signal goes to both projector and touch screen; (b) a wireless microphone for lecturing. Audio speaker play sounds from both the microphone and the computer.

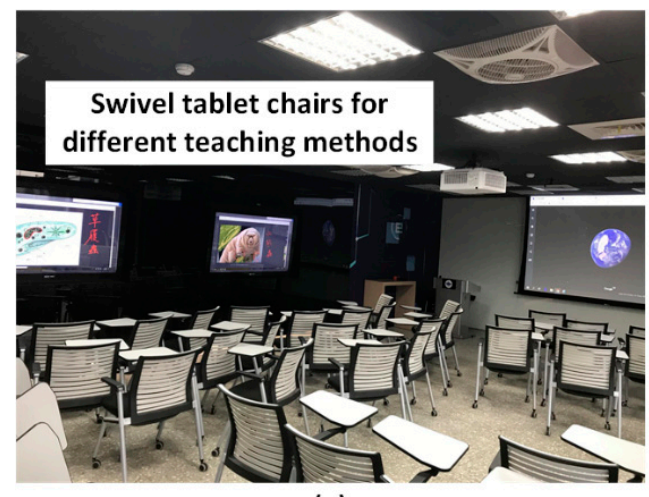

(a)

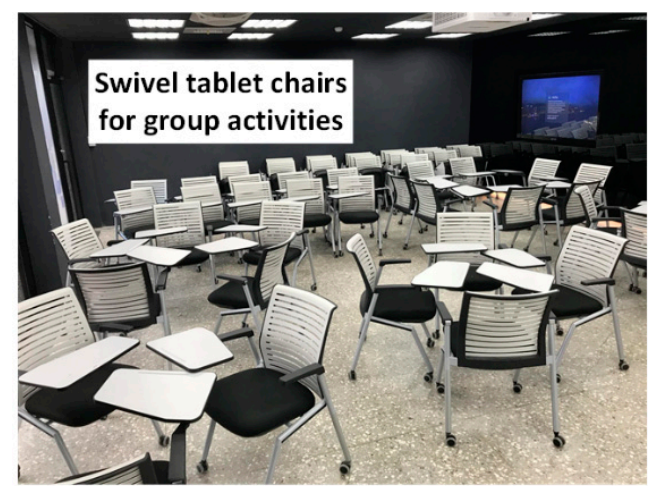

(b)

Figure 3. Swivel tablet chairs for dynamic seat rearrangement: (a) seats can be adjusted dynamically to face toward different interactive boards and (b) round table with any amount of seats. 


\subsubsection{From a Technology-Rich Classroom to a Smart Classroom}

When a classroom meets the basic requirements listed in the previous subsection, the classroom is ready for most classroom activities, including lectures, discussions, interaction, presentations and debate, supported by technology devices. A technology-rich classroom should have advanced functions or features, such as tele-education, interactive, automation, IoT devices, learning systems, environment control, and classroom management, to be a smart classroom. Technology or equipment needed to achieve smart classroom functions are described as follows:

1. Device control, as shown in Figure 4

- Doors with controllable locks and access system based on ID cards or biometrics.

- Every device in the smart classroom should be remotely controllable, at least ON and OFF.

- There should be an all-in-one user interface for people in the classroom to control the devices in the classroom.

2. Advanced interaction experience, as shown in Figure 5

- Besides the main large screen for lecturing, at least one more large screen with interactive function for group discussion and presentation.

- The extra-large screens are not only for interaction activities but also better audience experience when the classroom size is large. Therefore, a software or hardware solution for synchronizing contents between large screens is needed.

- Wireless display function for projecting contents to large screens from mobile devices

3. Image and audio recording, as shown in Figure 6

- At least two cameras, one points to dais or lectern while the other points to the audience for distance learning.

- Software or hardware to record the teacher's computer desktop.

- Images from cameras and computer desktop can be recorded or live cast depending on the smart classroom applications such as tele-education, webinar, courseware making, class monitoring, security, attendance management, lecture quality evaluation, and other image-based AI functions. 


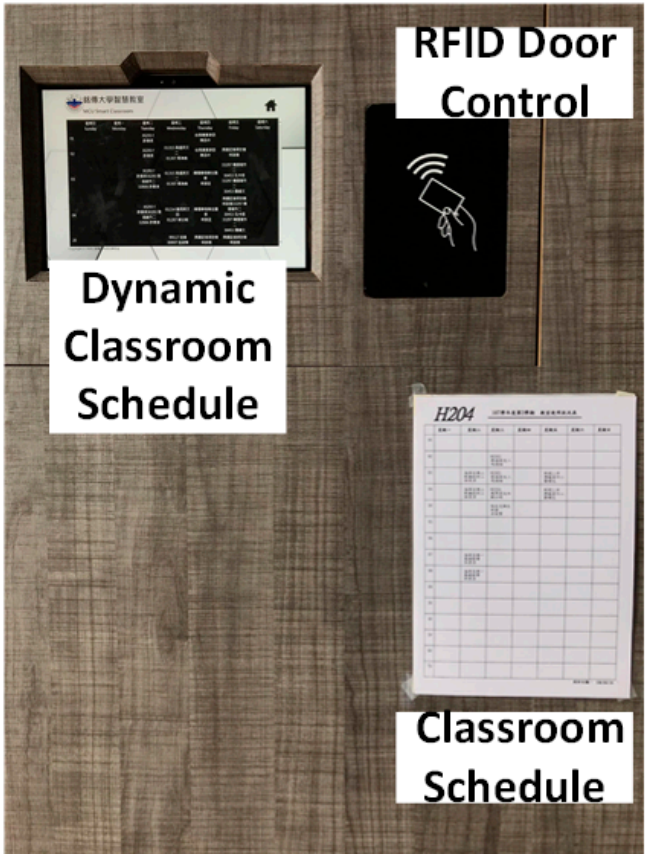

(a)

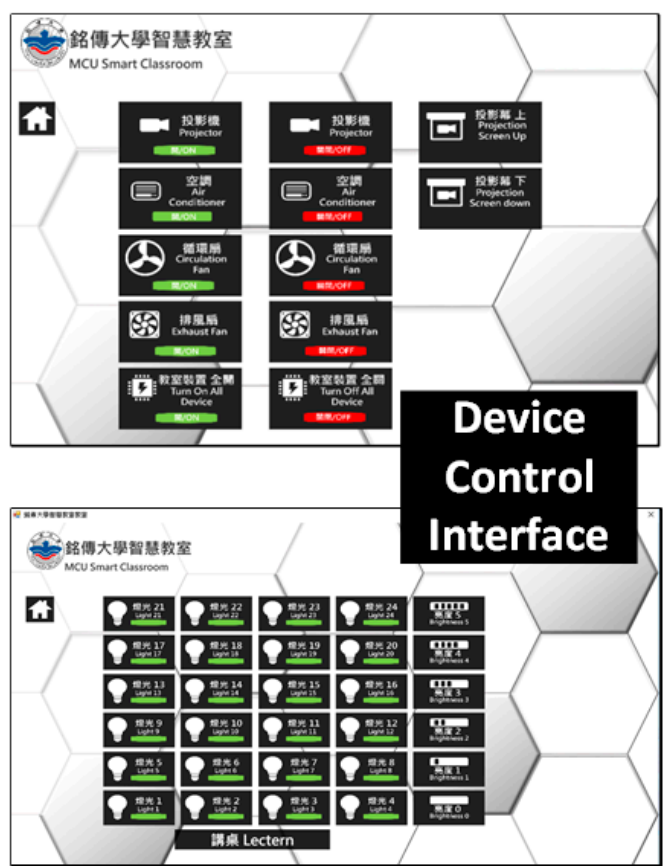

(b)

Figure 4. Device control: (a) an RFID-based door access system and an information board next to the front door. Dynamic classroom schedule's information is up to date while the paper schedule's information is outdated; (b) Device control user interface on teacher's computer to control fans, air conditioners, and lights.

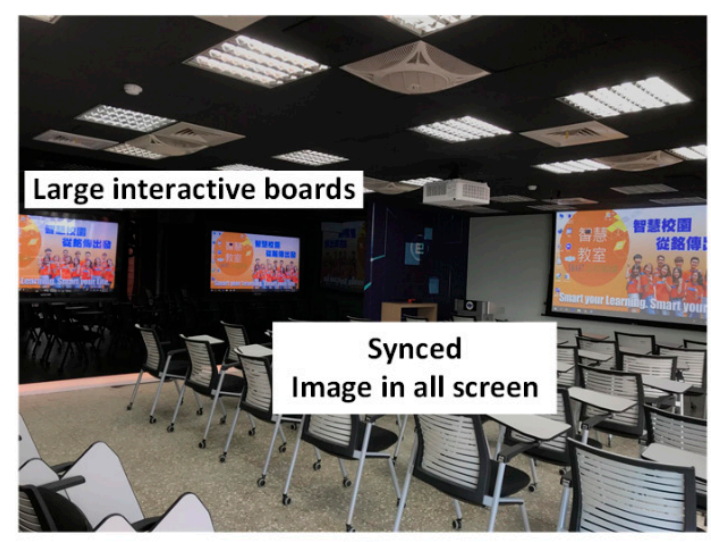

(a)

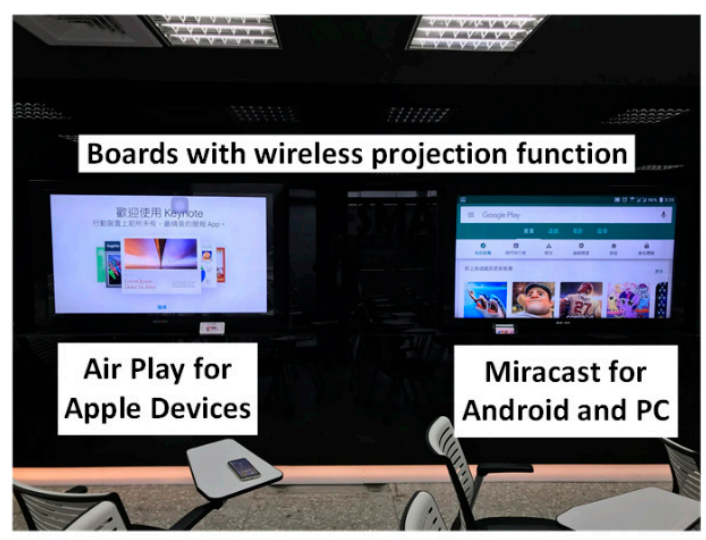

(b)

Figure 5. Advanced interaction experience: (a) large interactive boards for group discussion. Images can be synchronized on all screens; (b) wireless display function for interactive boards. 


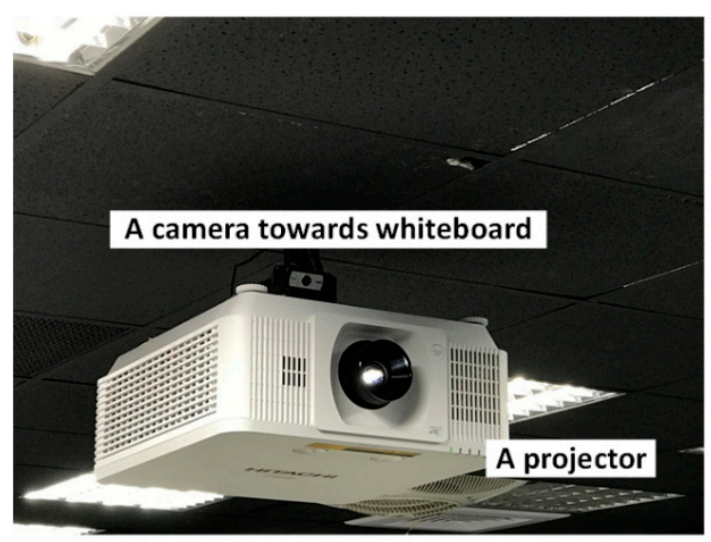

(a)

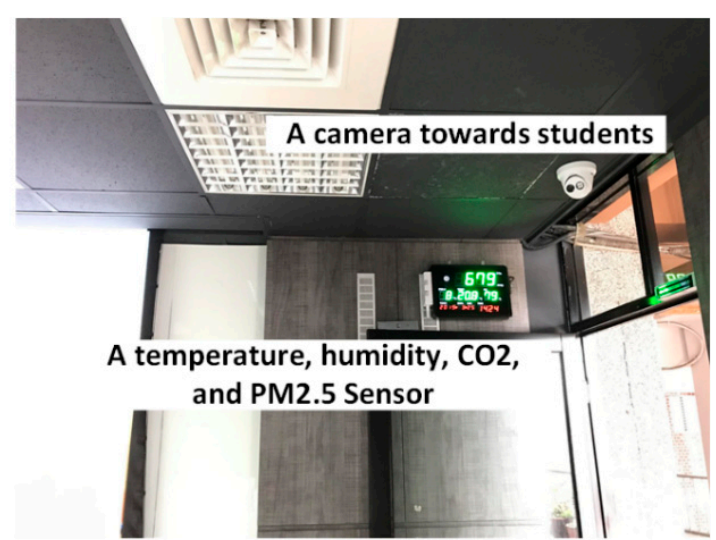

(b)

Figure 6. Image and audio recording: (a) a camera on the projector pointing towards the whiteboard; (b) a camera pointing towards students and a multi-function sensor which measures environment parameters including temperature, humidity, $\mathrm{CO}_{2}$ level, and PM2.5 level. PM2.5 means particulate matter which is smaller than 2.5 micrometers in diameter.

\subsubsection{Smart Classroom with Context Awareness}

When environment parameters are changing, classrooms with context awareness should be able to determine the reactions to take based on certain rules or AI algorithms. Therefore, a context-aware smart classroom should have sensors to retrieve environment data and highly integrated with the school information systems for getting user context.

1. An information board to show classroom context

- Classroom schedule should be shown in the information board. Therefore, as shown in Figure $4 \mathrm{a}$, the information about the classroom schedule is always correct even if a class is canceled or moved to another classroom.

- Classroom physical environment parameters, such as $\mathrm{CO}_{2}$ level, humidity, and temperature, can be shown in the information board, as shown in Figure 7.

2. Control actions should link to backend school information systems to get user context related to the classroom.

- When the classroom is empty according to the correct classroom schedule from the school information system, classroom door should be locked and all devices, except controlling devices, should be turned off automatically to reduce energy consumption.

- When the classroom is not empty according to the correct classroom schedule from the school information system, classroom door should be unlocked automatically and keep unlocked until the class is over.

- The door access system should link to teachers and students' private class schedule. Teachers and students who get to the classroom before the class can unlock the door and turn devices on with ID cards.

- When a user passes the door access system, devices in the classroom, which are essential to a class, should be turned on automatically.

3. Environment parameters related to teaching and learning performance should link to control actions

- $\mathrm{CO}_{2}$ level triggers or suggests exhaust fan actions.

- Temperature and humidity trigger or suggest air conditioner actions. 
- Illumine triggers or suggests light control actions.

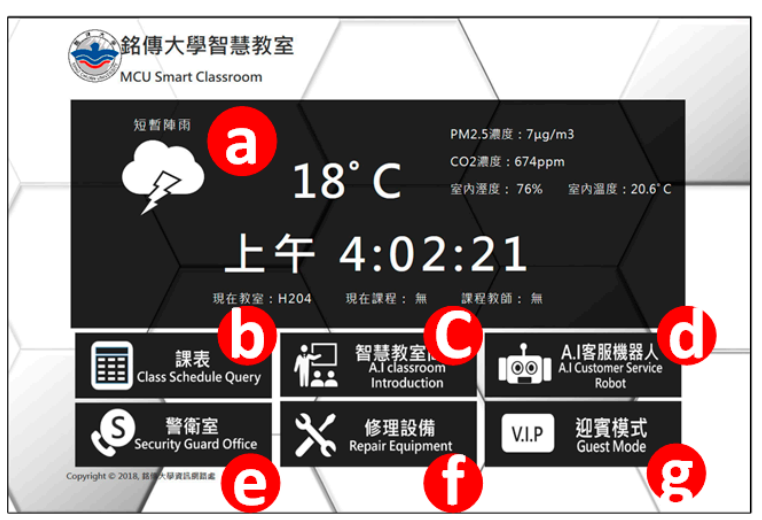

(a)

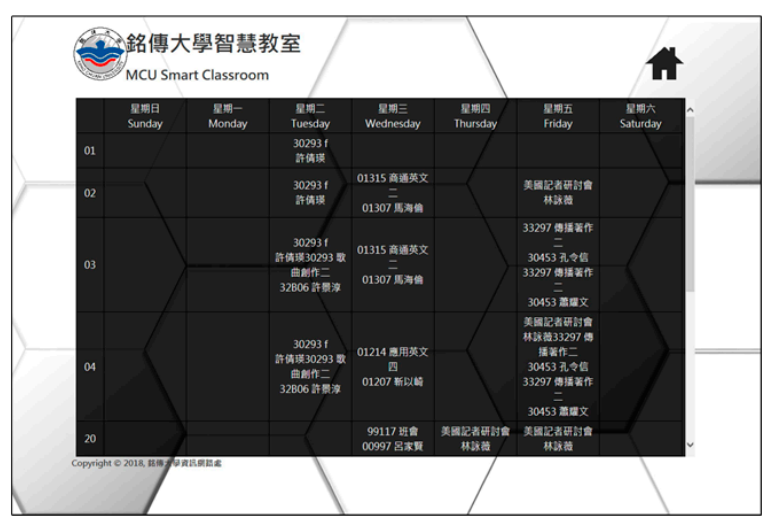

(b)

Figure 7. Information board can provide rich classroom context information and interactive functions: In part (a) of this figure, the board shows information including time, weather, class, $\mathrm{CO}_{2}$ level, $\mathrm{PM}$ 2.5 level, indoor temperature, and humidity in portion a. Users can get dynamic classroom schedule, which is shown in part (b), by pressing button $b$. The functions of button c, d, e, f, $g$ are 'Smart classroom introduction', 'launch a AI chatbot', 'Skype call to the security guards', 'Skype call to the IT services', 'Show welcome message'

\subsection{The Smart Classroom Technology Integration Model}

The building blocks of a smart classroom are sensors and devices. Engineers need to use different kinds of ways to access multiple devices to get accurate data or perform control actions in smart classrooms. It takes complex actions to perform a simple task. A real case is to get the average in-door temperature in a smart classroom remotely. To retrieve temperature level from different sensors, such as the air conditioner, a high-level environment sensor, and a simple digital temperature sensor, different communication technologies, such as Transmission Control Protocol (TCP), User Datagram Protocol (UDP), Simple Network Management Protocol (SNMP), Telnet, Secure Shell (SSH), RS485/422/232 serial communication, Modbus serial communications protocol, need to be used. It may not be a big problem in labs of schools of engineering in the short term, but it will be a major problem for running and maintaining a campus-wide smart classroom program in the long term because the integration and maintenance cost will be very high. Therefore, in this subsection, a technology integration model based on Raspberry Pi is proposed for the ease of smart classroom construction and smart classroom application development in terms of computer technology. The four layers of the proposed technology integration model are:

- $\quad$ Layer 1: The Device Integration Layer

- $\quad$ Layer 2: The Basic Operation Layer

- Layer 3: The Combo Operation Layer

- $\quad$ Layer 4: The Smart Classroom Application Layer

The proposed model provides standard rules to access underlying technologies from the top layer remotely. The functions and definitions of each layer are explained from the bottom layer to the top layer of this model. The layering concept is shown in Figure 8; the bottom layer of the proposed model is layer 1, which is the Device Integration Layer. In this layer, the Raspberry Pi was used to implement all direct device communications, including retrieve data from devices and send control commands to devices, within the scope of a smart classroom. Communication procedures between interfaces and protocols, such as TCP/UDP, Inter-Integrated Circuit $\left(\mathrm{I}^{2} \mathrm{C}\right)$, Serial Peripheral Interface (SPI), General Purpose Input Output (GPIO), RS422/485/232, Modbus, Bluetooth Low Energy (BLE), 
RFID, and ZigBee, should be implemented on the Raspberry Pi in this layer. All programming languages supported by Raspbian can be used to implement the communication procedures.

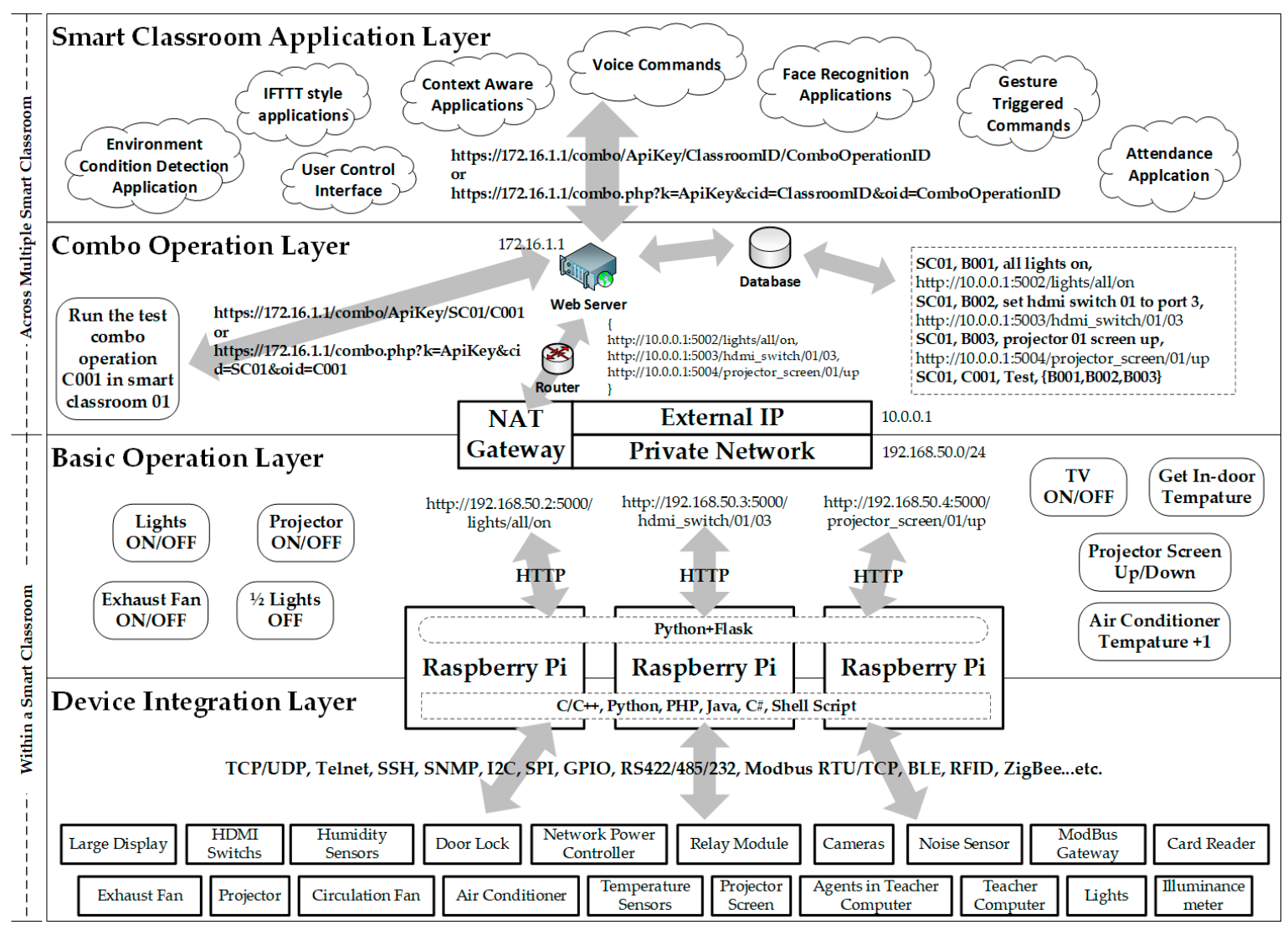

Figure 8. The smart classroom technology integration model.

The second layer of this model is the Basic Operation Layer. As shown in Figure 8, in this layer, the basic operations of a smart classroom were defined. All the defined operations were implemented as web service calls with Python [37] and Flask [38] on Raspberry Pi boards. When a basic smart classroom operation, such as turning off the air conditioner, is called through the web service call, the underlying control commands to the devices related to the operation will be invoked by the corresponding Flask route. With this layer, all direct device communications in layer 1 are hidden from users and applications. By sending HTTP requests, users and application can perform basic smart classroom operations defined in this layer. In the third layer, which is the Combo Operation Layer, basic operations are combined to form a combo operation. As shown in Figure 8, operations involved in executing more than one basic operation, which is defined in layer 2, should be defined and implemented in this layer. Therefore, a central web server with database linkage is needed. Any web server, web application, and database technology can be used to build this layer. The basic operations in layer 2 need to be registered in the database. Combo operations should be implemented as web service calls on the central server. When a combo operation, such as pull down projector screen and turn off lights near the projector screen, is called, the layer 2 operation to pull down the projector screen and the layer 2 operation to turn off lights near the projector screen are invoked by the corresponding layer 3 web service call. By sending HTTP requests to the central server, users and application can perform combo smart classroom operations defined in this layer. The top layer of this model is named Smart Classroom Application Layer. A smart classroom application contains logics or means to determine ways of controlling smart classrooms. As shown in Figure 8, applications related to user context, authentication, authorization, user interface, voice command, attendance control, door access control, actions triggered by AI algorithms, actions trigger by management rules, actions triggered by sensor data, and scheduled actions should be implemented in this layer. 
All layers in this model, components in each layer, and the interactions between components in different layers are illustrated in Figure 8. Communication details between different devices and Raspberry Pi in a smart classroom are handled in layer 1. Sensors or devices with the same function may have different control protocols or communication standards in layer 1 . With layer 2 , a function, such as turn on air conditioner number 1, can be defined as a basic operation for every smart classroom and implemented as a unified web application interface. Therefore, even if air conditioners in smart classrooms have different control protocols. Central control applications still can turn on the air conditioners in all smart classrooms by sending a unified web application interface call with parameters such as classroom id. Basic operations are registered in the database in layer 3. Therefore, combo operations in layer 3 can be made based on basic operations in layer 2. Thus, a combo operation to turn off air conditioners in all smart classroom can be easily defined and implemented in layer 3. Consequently, teachers, administrators, and software developers only need to focus on developing high level or complex smart classroom applications, such as AI applications, in layer 4. For example, if a teacher is developing context-aware applications for smart classrooms under the proposed architecture, the teacher can get sensor data through the standard web application interface calls defined in layer 3 and feed the retrieved data to the self-developed application in real-time. When the context-aware application decides to control certain devices in smart classrooms, related combo operations can be launched through the corresponding web application interface calls defined in layer 3 . The teacher does not need to know any control details in layer 1.

\subsection{Supporting Measures for the Proposed Architecture}

The proposed model is a conceptual technology integration model and is beneficial to high level and campus-wide smart classroom applications in terms of underlying technology integration. This model is not intended for addressing issues such as security, networking, and daily operations. Therefore, supporting measures are also proposed in this architecture for successfully adopting the proposed classroom prototype and technology integration model in smart campus programs. Two important supporting measures related to network configuration are:

- Device control network, which is layer 1 and layer 2 in the model, and normal network, which is layer 3 or layer 4 in the model, should be at least logically separated in smart classrooms.

- Every classroom should have its own private network for device control, and the configuration of the private network in every classroom should be identical.

In Figure 8, a network gateway is placed between layer 2 and layer 3, which means the network design of the proposed model, in terms of device control, is based on IP network and every classroom should have its own private IP network for device control and network traffic not related to classroom device control should be separated from the device control network. The major reason to separate control and the normal network is security. The public computer and IoT devices are both vulnerable. However, normally IoT device vendors will not provide system patch as frequently as operating system vendors. Even if an IoT device has a new security patch, it is still not having efficient methods, such as automatic update, for massively deploying security patches to IoT devices. Therefore, it is very dangerous and not recommended to put the classroom public computers and smart classroom IoT devices in the same network. Multiple smart classrooms using the same IP network for device control is also not recommended in the proposed architecture, which means every smart classroom should have its own private network for device control and the configuration of the private network in every classroom should be identical. The major reason for this policy is the efficiency of classroom application development, device operation, and management. With this policy, the use of IP address should be well planned for the devices in the control network because there will be only one private network configuration for every classroom. For example, if projectors in every classroom are all using 192.168.50.100, and the Raspberry Pi boards in every classroom, which are responsible for controlling the projector in the same classroom, are all using 192.168.50.2, the program and configuration related 
to sending control commands from the controlling Raspberry Pi to the controlled projector can be used in all classrooms without any modification. Raspberry Pi boards, which are playing the same role and performing identical functions in different smart classrooms, should have identical IP configurations. This rule also applies to Layer 1 devices with the same model number and playing the same role in the different smart classrooms. Therefore, device configuration and device control procedure programming efforts can be minimized with this policy and the only network configuration for device control differs from classroom to classroom is the external IP address of the NAT gateway for each classroom. Therefore, the central control server only needs to know the external IP address of each classroom for delivering layer 2 operation commands to each classroom.

Although the proposed architecture does not have other rules for issues related to network security and management. Mechanisms helpful to enhance security and manageability while implementing the proposed architecture still need to be considered, for example:

- It is recommended to use Secure Sockets Layer (SSL) encryption to protect web application interface calls.

- It is recommended to implement mechanisms such as API keys for controlling access to layer 2 and layer 3 operations.

- It is recommended to implement or set IP and port-based access control rules for controlling access to web application interface calls.

- It is recommended to take software-based Network address translation (NAT) solutions for private network gateway in each classroom for providing flexibility and convenience of future configuration.

- It is recommended to implement auto registration functions on Raspberry Pi boards for auto-registering layer 2 operations to the central web server.

For running multiple smart classrooms in a smart campus, methods for rapidly handling smart classroom related technical issues are important. Therefore, another important supporting measure in the proposed architecture is to build a virtual smart classroom, logically or physically, for technical support activities such as problem reproduction, problem resolving, device configuration, device function validation, application development, and function experiment with using physical smart classrooms. The concept of virtual smart classrooms can be helpful for building and running many smart classrooms in a smart campus. Although a virtual smart classroom for technical support can be a logic network environment with hardware and software or a physical environment, such as a lab, for supporting daily operations of smart classrooms. The key point for a virtual smart classroom to play a part in the smart classroom project is that the network configuration of the virtual smart classroom should be the same with other smart classrooms like previous supporting measures requested, which means the virtual smart classroom should be logically, in term of network, working like a real smart classroom. Thus, software and hardware can be configured and well tested before deployed to the real smart classrooms, which enables high quality and rapid technical support. Compare to other works related to smart campus with similar architecture with this work [79,80,82]; this study is focused on defining essential parts of a context-aware smart classroom prototype for supporting teaching and learning activities. The technology integration model in this study is designed for implementing and extending smart classroom functions and applications rapidly. With the supporting measures, smart classroom deployment and management can be done efficiently.

\section{An Implementation of the Proposed Architecture}

In this section, a minimal implementation of the proposed architecture is used to demonstrate the advantages of the proposed architecture. As shown in Figure 9, a simplified context-aware smart classroom, which is named as H204, is designed based on the proposed smart classroom prototype. A function of a sample control application is used for illustrating the operation procedures in the proposed technology integration model, and a context-aware energy saving application is 
designed based on the proposed model. The network configuration in this implementation is following the proposed supporting measures. Finally, a physical model house is demonstrated to explain the concept of virtual smart classrooms. Devices in H204 are list as follows:

- A projector

- A motorized projector screen

- Four light sets which can be controlled separately

- Doors with electromagnetic locks

- RFID based door access control

- An exhaust fan

- An air conditioner

- A sensor for $\mathrm{CO}_{2}$ level and temperature

- A wall mount interactive board

- Three Raspberry Pi boards for device control

- An IP NAT gateway

- A Web Server in the university network

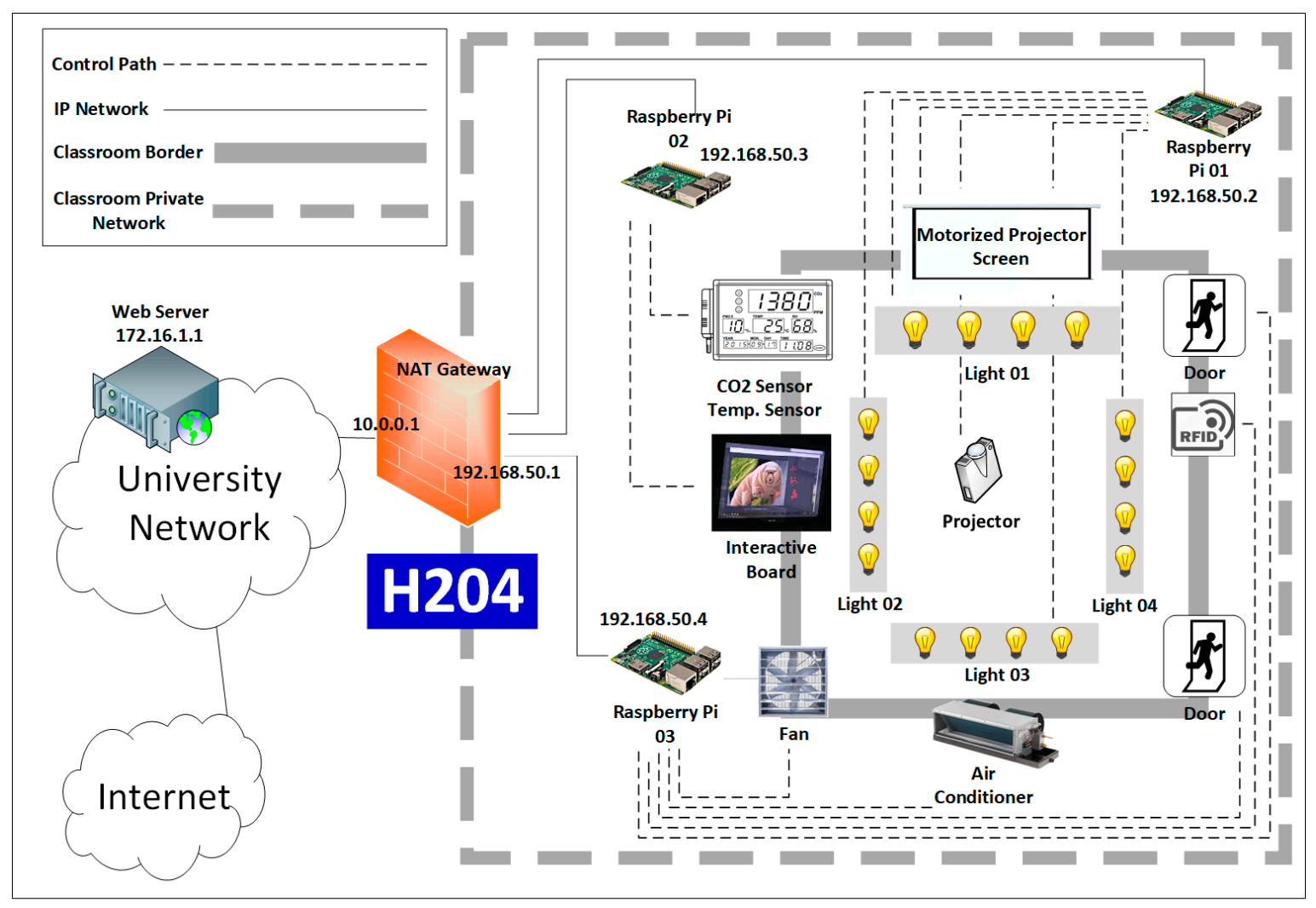

Figure 9. A smart classroom designed and configured based on the proposed architecture.

The control path line in Figure 9 represents that a device is controlled by the connected Raspberry Pi. A controlled device does not need to connect to the controlling Raspberry Pi directly. The ways that Raspberry Pi communicate with the controlled devices are varied depending on the controlled devices. Network configurations, such as Internet Protocol (IP) address, of Raspberry Pi boards are also shown in Figure 9. The devices with Ethernet control interface or connected to an Ethernet bridge are not illustrated in Figure 9. Three Raspberry Pi boards are used in the sample smart classroom. Network configurations, the devices controlled by Raspberry Pi boards in Figure 9, and the way that Raspberry Pi boards control the connected devices are described as follows: 
- Raspberry Pi 01: IP address is 192.168.50.2. The projector, projector screen, all four light sets are controlled by Raspberry Pi 01.

- Raspberry Pi 02: IP address is 192.168.50.3. The interactive board and the environment sensors are controlled by Raspberry Pi 02.

- Raspberry Pi 03: IP address is 192.168.50.4. The RFID tag reader is connected to Raspberry Pi 03. Doors, air conditioner, and exhaust fan are controlled by Raspberry Pi 03.

- NAT Gateway: The private network of the sample smart classroom is 192.168.50.0/24. The IP address of the network interface connecting to the private network is 192.168.50.1. The IP address of the network interface connecting to the university network is 10.0.0.1.

- Web Server: The web server is located in the university network. The IP address of the web server is 172.16.1.1

\subsection{Device Integration Layer and Basic Operation Layer}

Layer 1 is where various kinds of devices are located. In the proposed technology integration model, all direct device control operation need to be implemented in layer 1 . In this subsection, physical and logical connections between controlled devices and Raspberry Pi boards in H204 are described in Table A1. As shown in Table A1, devices with various kinds of control interfaces, such as RS232, RS485, Modbus, TCP, GPIO, are linked to Raspberry Pi boards. And control commands corresponding to device actions are sent from Raspberry Pi boards, by shell commands, programs, python scripts, or PHP CLI scripts, to the controlled devices, including a projector, a motorized projector screen, four light sets, an interactive board, a temperature sensor, $\mathrm{C}_{2}$ sensor, an exhaust fan, an air conditioner, and electromagnetic door lock.

After control commands corresponding to actions on devices are implemented and tested on Raspberry Pi boards in layer 1, layer 2 basic operations can be defined as a web application interface calls and implemented with Python and Flask. The mappings of layer 1 device actions to the corresponding layer 2 basic operation web application interface calls in H204 are shown in Table A2. With layer 2 basic operations web application interface calls and proper network configurations, device actions in $\mathrm{H} 204$ can be called from the central web server. Then layer 3 combo operation web application interface calls be defined and implemented on the central web server.

\subsection{Combo Operation Layer and Smart Classroom Application Layer}

In the proposed model, the Raspberry Pi boards are located in the smart classrooms' private network, and a central web server is necessary for implementing combo operations and controlling all smart classrooms. The way for the central web server to access the layer 2 basic operations on Raspberry Pi boards is the port redirection settings, as shown in Table A3, on the NAT gateways of smart classrooms.

Table A4 is a sample for showing how layer 2 operations are registered on the central web server. If the devices in a smart classroom do not need to be controlled outside the classroom, then the central web server is not needed because layer 2 operations can be sent from a control device located physically and logically in the smart classroom. However, the proposed smart classroom architecture is not only for building one smart classroom. Therefore, a central web server for registering layer 2 basic operations, defining layer 3 combo operations, and implementing other smart classroom control logics are necessary for the proposed architecture. The way of registering and recording layer 2 operations on the central web server can be implemented in different methods such as automatic register by the Raspberry Pi boards or manually predefined.

Table A5 shows the way of implementing layer 3 combo operations on the central web server. Once a combo operation is defined, it can be called by any other application by sending HTTP requests. Multiple layer 2 basic operations will be triggered once a layer 3 combo operation is called. Therefore, complex smart classroom control logics, such as context-aware applications, can also be implemented, on or off the central web server, without any knowledge of direct device control. 
In Figure 10, the complete operation flow triggered by a Mobile App is demonstrated while a button for turning on all devices in $\mathrm{H} 204$ is pressed. In procedure A, the Mobile App sends a web application interface call to the central web server using classroom ID and layer 3 operation ID as parameters. When the central web server takes the call, corresponding layer 2 operations are founding in procedure B and C. Then the central web server sends multiple layer 2 operations, which are HTTP requests, to the NAT gateway of H204. In procedure D, when the NAT gateway of H204 gets the HTTP requests, addresses and ports are translated according to the port redirection settings on the NAT gateway. Then the HTTP requests are forward to Raspberry Pi boards, as shown in procedure E. Finally, in procedure F, the layer 2 operations are executed on the Raspberry Pi boards, and the corresponding device control commands are executed. Therefore, all devices are turned on by a simple click in a layer 4 smart classroom application. In Figure 11, the operations described above are shown as a sequence diagram.

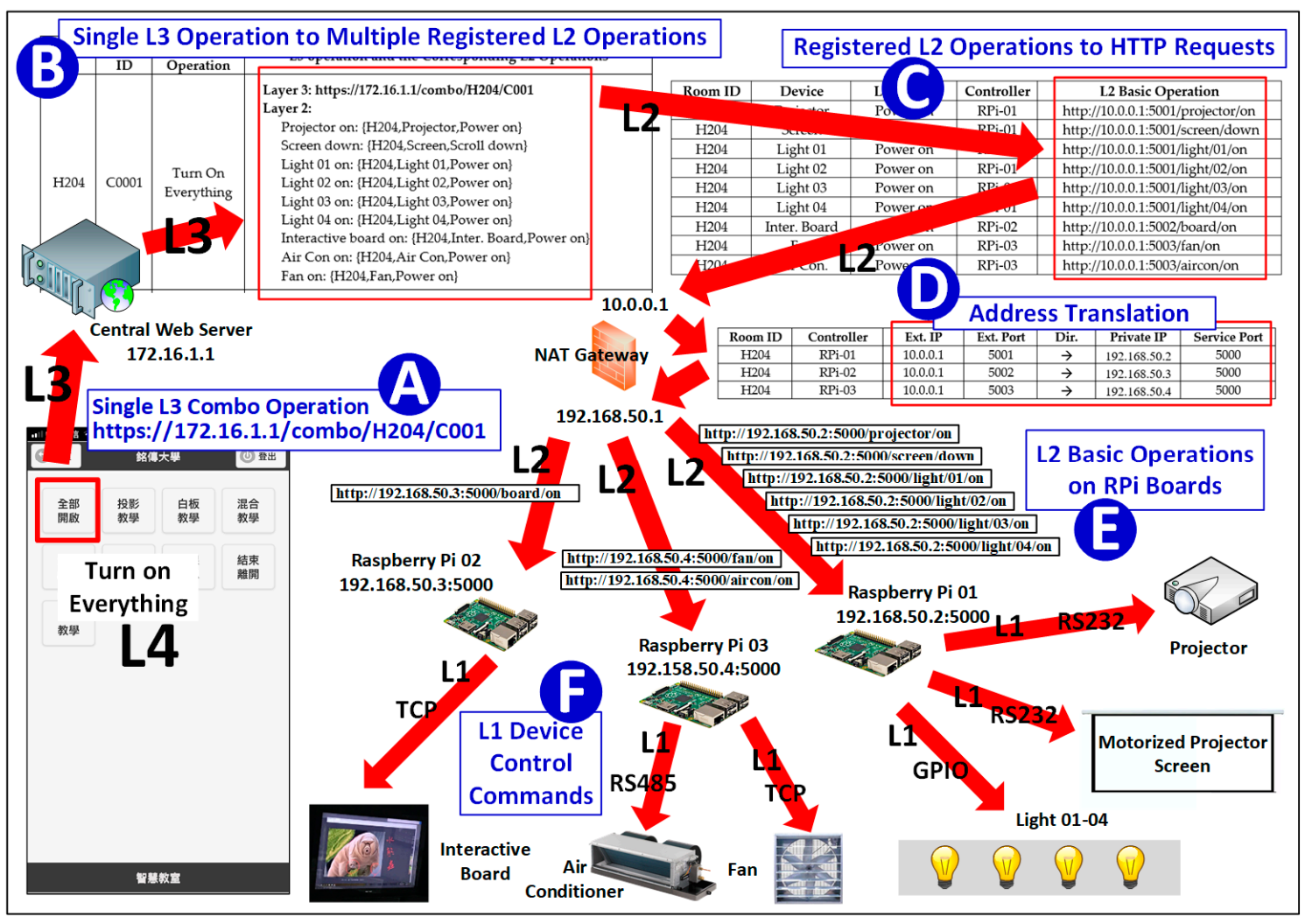

Figure 10. Operation flow in an implementation of the proposed model. 


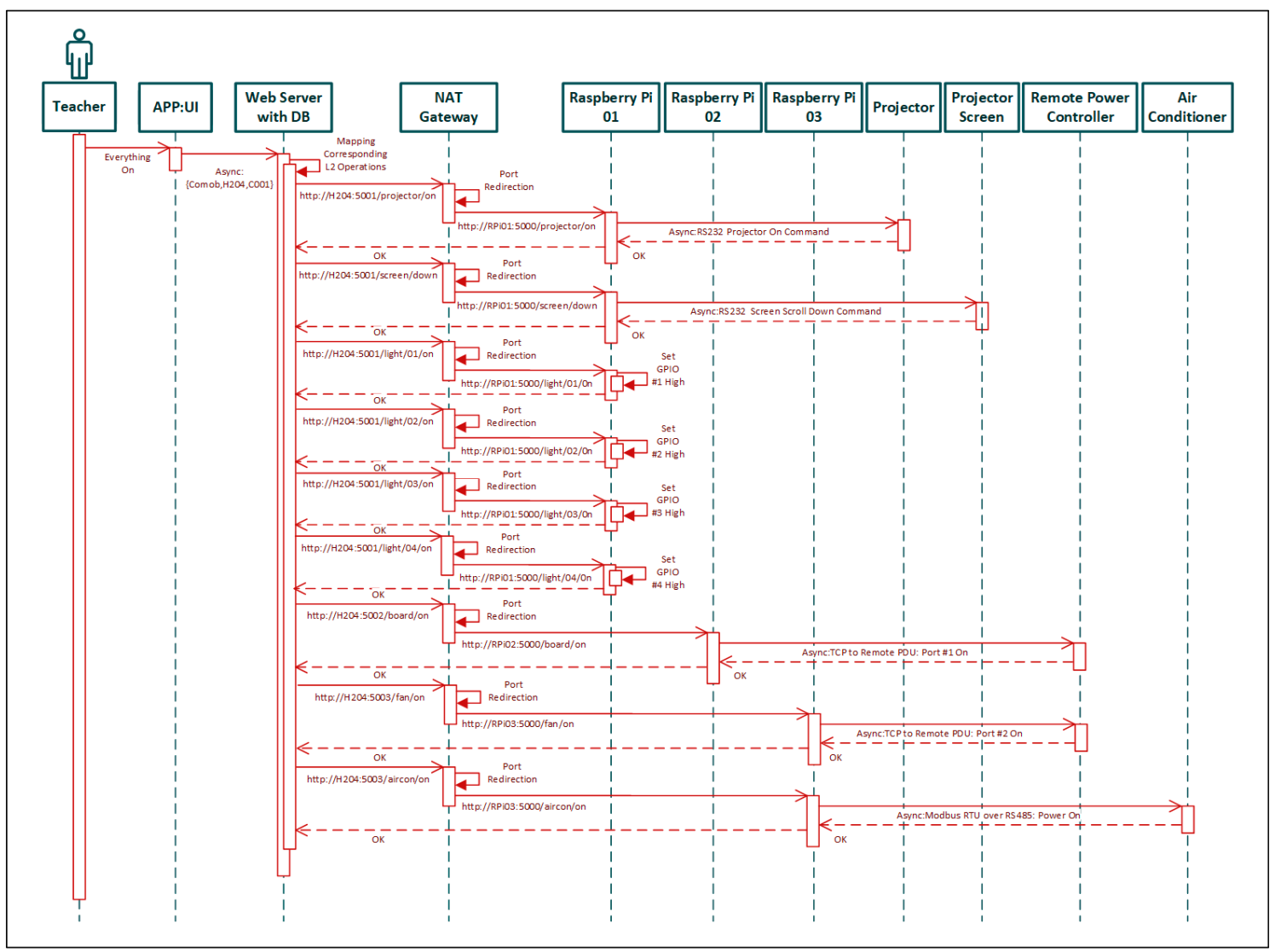

Figure 11. Sequence diagram of the operation described in Figure 10.

\subsection{Context-Aware Energy-Saving Smart Classroom Applications}

In the previous subsection, the way of using the proposed architecture was explained with a minimal implementation of a smart classroom called H204. For demonstrating that context-aware energy-saving smart classrooms can be easily implemented with the proposed architecture, an application for manually control classroom devices for saving energy in different teaching scenarios and the logic of a context-aware energy saving application is described in this subsection. Figure 12 is a mobile application for teachers to set devices to predefined configurations in smart classrooms for different teaching scenarios in H204. Different devices will be turned on or off depending on the selected scenario. For example, when the teacher wants to use the whiteboard, then the projector will be turned off, and the screen will be scrolled up. When the teacher wants to use the projector, then the projector will be turned on, the screen will be scrolled down, and the lights near the screen also need to be turned off. When the teacher wants students to have a group discussion with the interactive boards, the projector will be turned off, the screen will be scrolled up, the interactive boards will be turned on, and the lights near the interactive boards will be turned off. Table A5 implements functions such as teaching with the projector (C0002), teaching with the whiteboard (C0003), group discussion (C0004) and turn off everything (C0005) in H204. As shown in Table A5, devices not needed in certain scenario will be turned off for saving energy. 


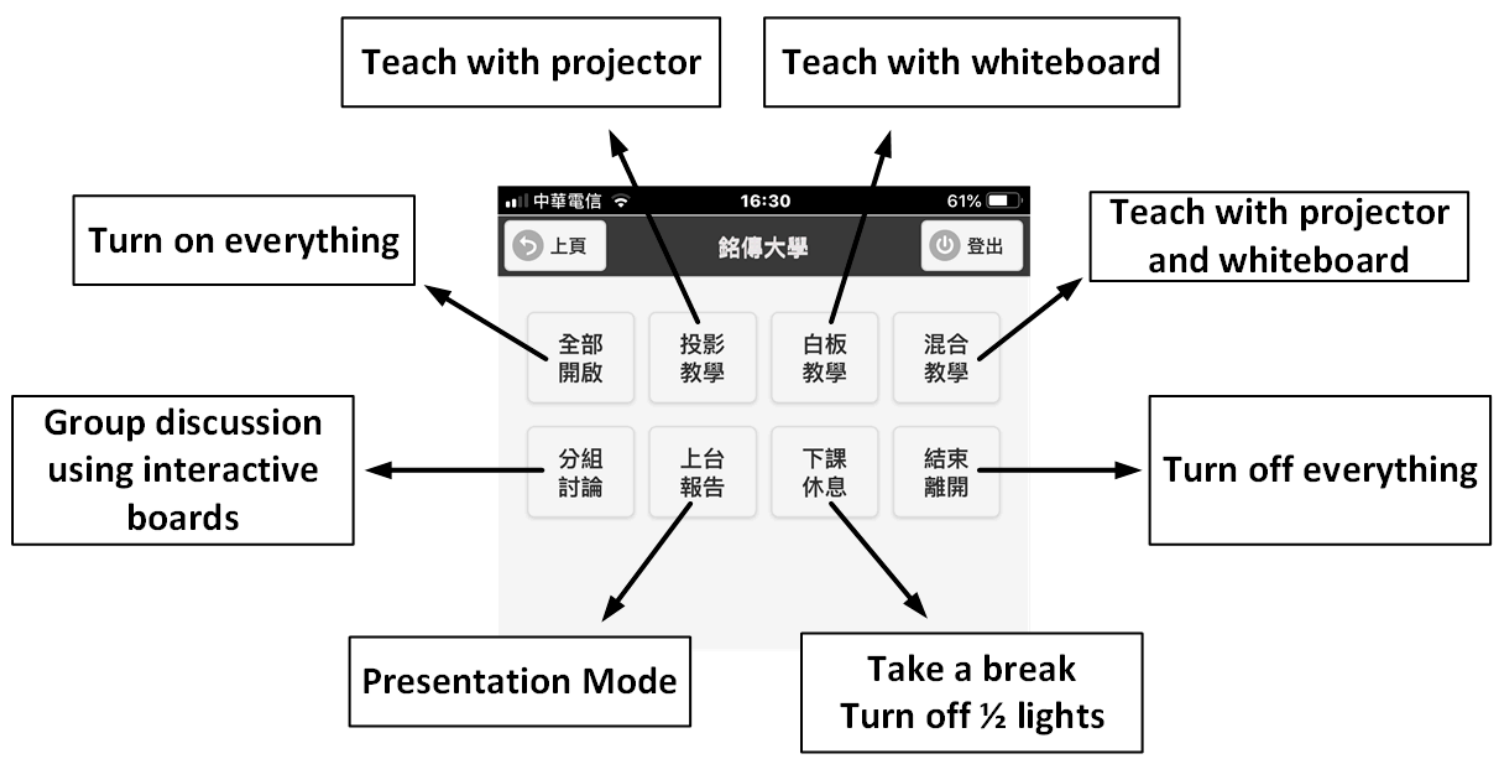

Figure 12. A mobile phone application for teachers to set devices to predefined configurations in smart classrooms for different teaching scenarios. As the explanations in this figure, the functions of the buttons in the top line from left to right are 'Turn on everyyhing', 'Teach with projector', 'Teach with whiteboard', and 'Teach with projector and whiteboard'. The functions of the buttons in the bottom line from left to right are 'Group discussion using interactive boards', 'Presentation mode', 'Take a break', 'Turn off everything'.

Figure 13 shows the procedure of a context-aware energy-saving smart classroom application for H204. The procedure scheduled to run once a minute. Devices in an empty classroom will be turned off automatically for saving energy. Doors, fans, and air conditioners will be controlled depending on sensor data and real-time classroom schedule. A very important thing for time-based energy saving policy is that the classroom controlling application must link to the real-time dynamic classroom schedule in the school information systems; otherwise, energy will still be wasted when the real classroom schedule is changed for any reason. The idea of this energy saving application is based on previous studies including References [58,66-69]. With the proposed model, low-level device control details can be packed as web application interface calls. Therefore, if the campus or building provides selectable energy source, high-level energy management control logic, such as Reference [63-65] can be implemented as layer 4 applications in the proposed model without handling different kinds of device control protocols. 
GET H204 real-time classroom schedule FROM the school information system

GET the ON/OFF status of all devices in H204

IF there is a class in $\mathrm{H} 204$ now

GET temperature in $\mathrm{H} 204$ from sensor

GET CO2 level in $\mathrm{H} 204$ from sensor

IF the temperature in $\mathrm{H} 204$ is greater than 26 Celsius AND the air conditioner is OFF

THEN turn on the air conditioner

IF the temperature in $\mathrm{H} 204$ is less than 24 Celsius AND the air conditioner in ON

THEN turn off the air conditioner

IF the $\mathrm{CO} 2$ level in $\mathrm{H} 204$ is greater than 1000 ppm AND the exhaust fan is OFF

THEN turn on the exhaust fan

IF the $\mathrm{CO} 2$ level in $\mathrm{H} 204$ is less than 800 ppm AND the exhaust fan is ON

THEN turn off the exhaust fan

IF there is no class in $\mathrm{H} 204$ now

GET door status of $\mathrm{H} 204$

IF there is a class in $\mathrm{H} 204$ in next 10 minutes AND the door is locked

THEN unlock the doors AND turn on $50 \%$ of lights

IF it has been 10 minutes after previous class

IF the doors are unlocked

THEN lock the doors

FOR each device

IF the device is ON

THEN turn off the device

Figure 13. A context-aware energy saving procedure for a smart classroom based on classroom schedule and sensor data running once a minute.

\subsection{In-Campus Facial Recognition Service Integration}

With the proposed technology integration model, applications can be easily integrated with smart classrooms. For example, a door access control application based on facial recognition technology can be easily implemented by integrating existing facial recognition cloud service and school information system. Figure 14 shows the face registration screen of an in-campus facial recognition cloud service made for smart meeting rooms. With the facial recognition cloud service, meeting attendance registration in the smart meeting rooms can be done with face instead of RFID solutions. For smart classrooms, a facial recognition client application can be implemented and deployed to the information boards next to the front doors of smart classrooms.
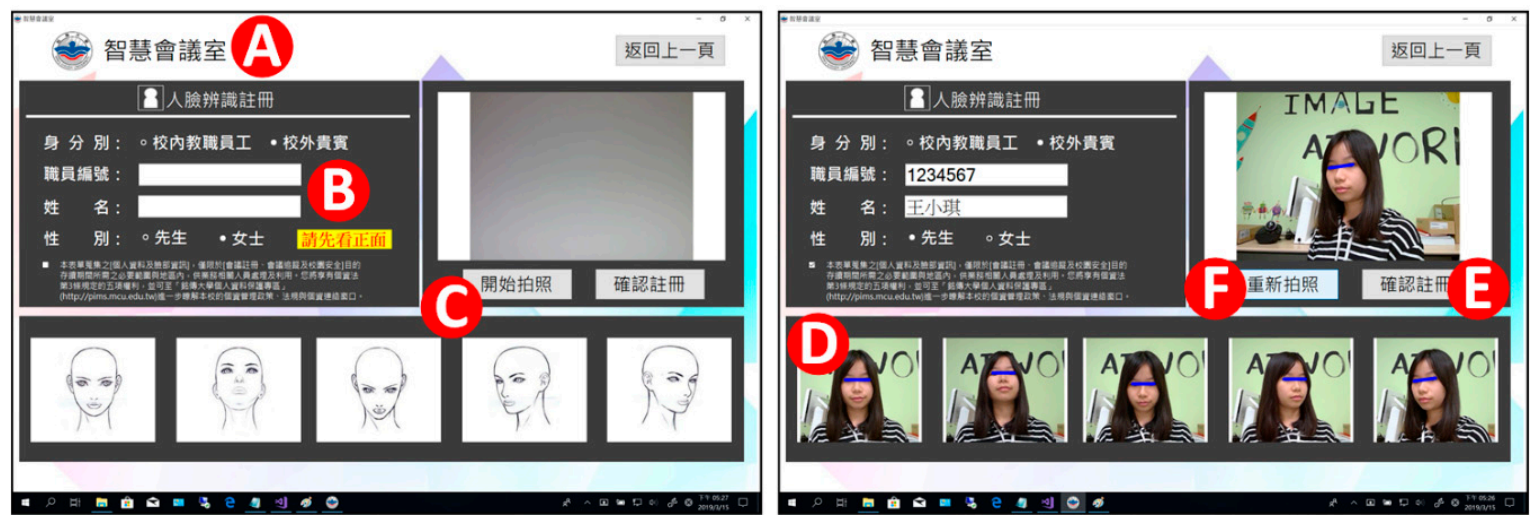

Figure 14. The face registration screen of an in-campus facial recognition cloud service. Portion A is the title of the screen which means 'Smart Meeting Room'. This screen is for users to register their face 
for facial recognition applications. In portion B, users need to enter user information, such as user type, employee id, name, gender, and agree the 'Personal Data Collection Agreement'. Then users press button $\mathrm{C}$ to start to take photos. The program will take 5 photos in different angle. Then users press button $\mathrm{F}$ to retake photos or press button $\mathrm{E}$ to finish the registration process.

TAKE photo FROM the camera on the information board

CALL the facial recognition cloud service by sending the captured photo

IF the face is recognized as a teacher OR a student

GET personal class schedule FROM the school information system

GET door status of $\mathrm{H} 204$

IF the person has a class in $\mathrm{H} 204$ (now OR in next 10 minutes) AND the door is locked

THEN unlock the door AND turn on $50 \%$ of lights

GET the ON/OFF status of all devices in $\mathrm{H} 204$

FOR each device

IF the device is OFF

THEN turn on the device

Figure 15. A facial recognition door access control procedure for smart classroom.

The client application captures faces with the camera on the information board, send the picture to the backend cloud service, get the facial recognition results, then send L3 combo commands to control smart classroom depending on the predefined rules. Figure 15 shows the procedure of the integrated facial recognition application in smart classrooms. Teachers and students, who have registered their face before and have class in this classroom, can unlock classroom door using their face instead of RFID identity cards.

With the proposed technology integration model, low-level hardware control operations in smart classrooms are defined as standard functions. High-level applications can access smart classroom functions with web application interface calls. As a result, smart classroom functions can be easily extended by linking different kinds of services.

\subsection{Implementation of the Proposed Supporting Measures.}

To implement the concept of the virtual smart classroom, which is one of the proposed supporting measures, a model house was made. As shown in Figure 16, the model house is designed based on the real smart classroom; application development and technical support related activities can be performed with the model house while real smart classrooms are occupied frequently. 


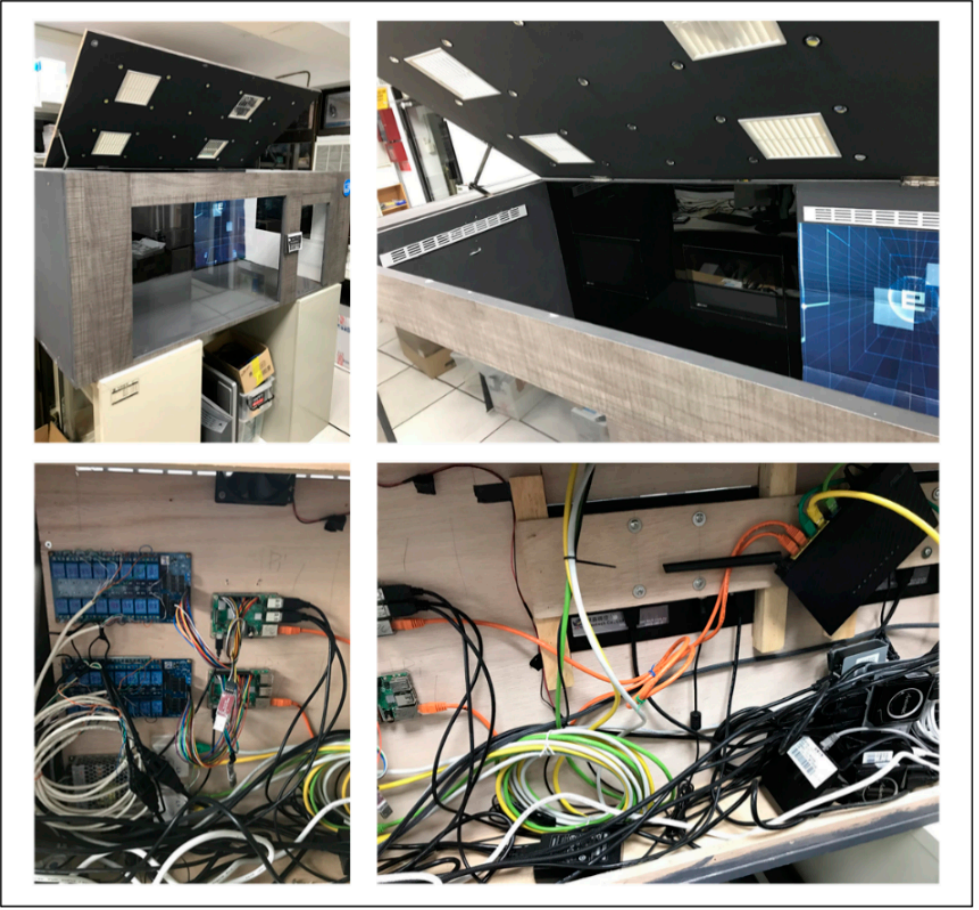

Figure 16. The concept of virtual smart classroom implemented by a physical model house.

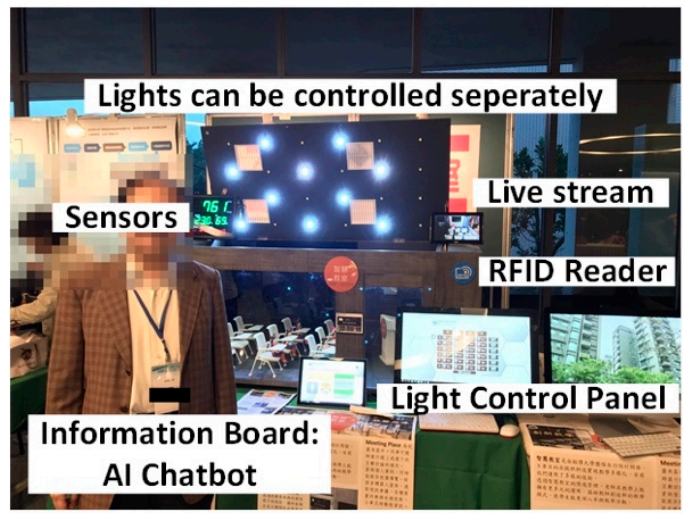

(a)

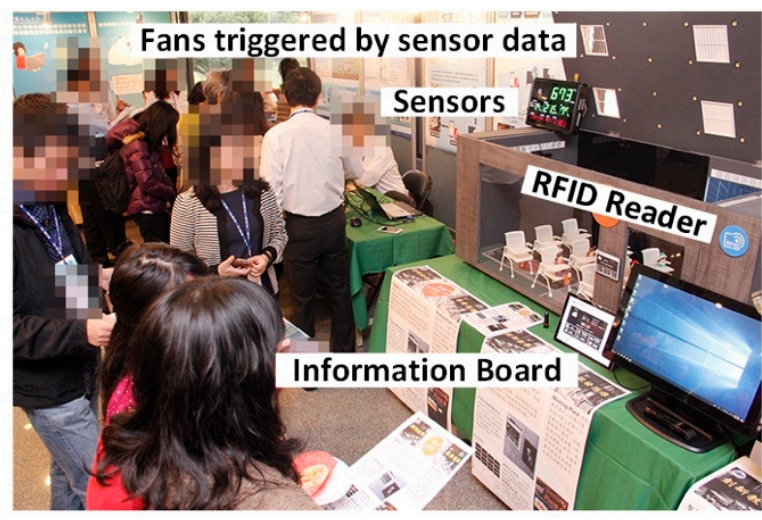

(b)

Figure 17. Smart classroom model house demonstration in International Conference on Smart Campus and Exhibition 2018. Most smart classroom functions are re-implemented with Raspberry Pi, Python, and PHP: (a). Lights can be controlled separately with a mobile phone and control panel. A camera toward the whiteboard is live streaming real-time classroom situation; (b) context-aware functions are also implemented, fans on the model house are triggered by $\mathrm{CO}_{2}$ levels. The RFID reader is used to control the door lock of the model house.

Figure 17 shows that the model house was demonstrated in a showcase of the International Conference on Smart Campus and Exhibition in November 2018 (iCSC\&E 2018) [85]. The model house is playing an important part in smart classroom application development. With the model house, most smart classroom applications can be developed and tested without going to a real smart classroom. In this showcase, Raspberry Pi is used to re-implement most functions of the MCU Smart Classroom. Although smart classroom functions are complicated combinations of various kinds of device control actions. It takes less than two weeks to implement all the functions that are planned to be demonstrated in iCSC\&E 2018. As a result, Raspberry Pi has been proven as a very productive tool for developing context-aware smart classroom applications, and a good model house can boost 
the process of developing smart classroom applications, which validates the concept of the virtual smart classroom in the supporting measures of the proposed architecture.

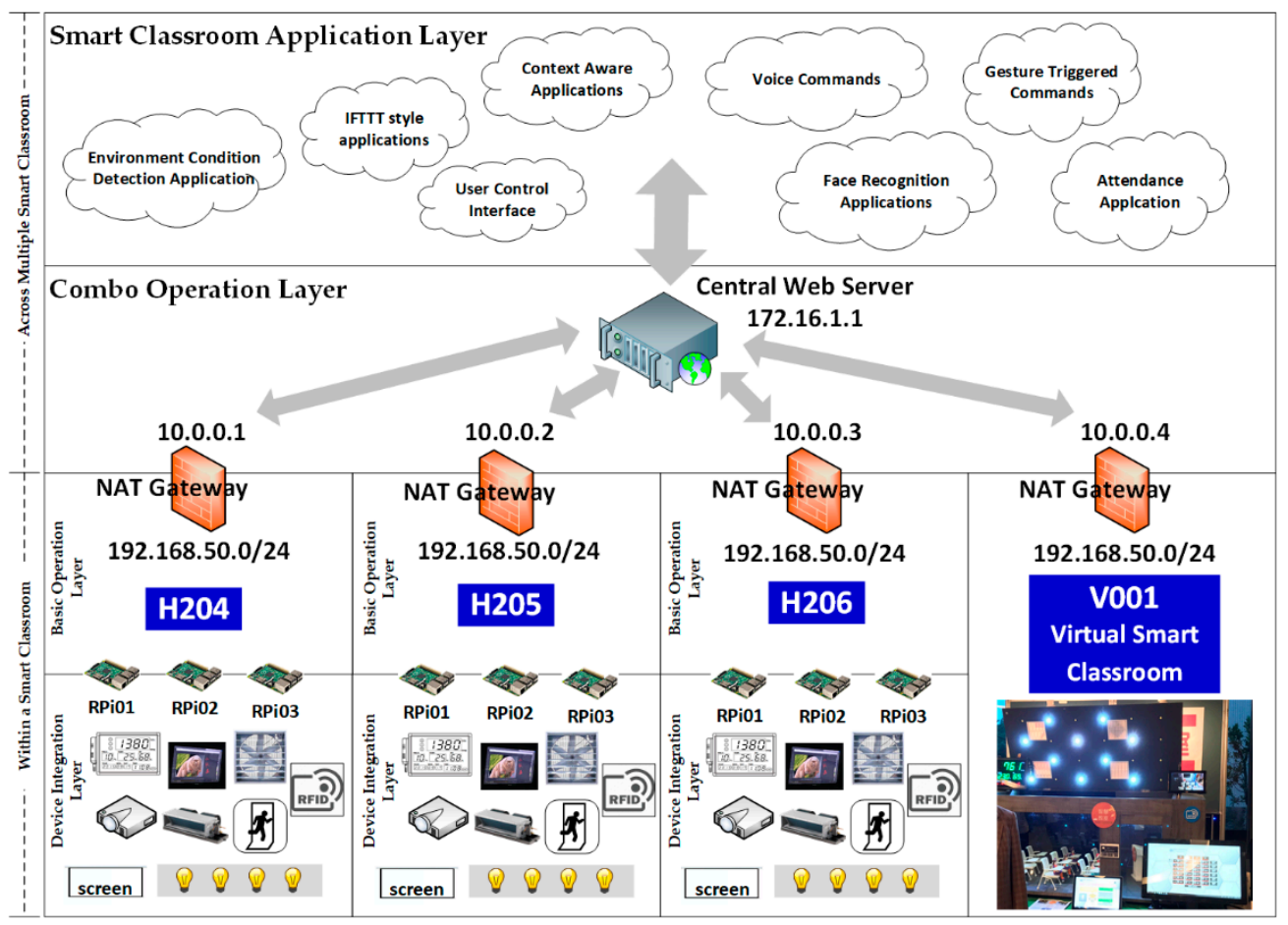

Figure 18. A campus-wide view of the smart classrooms based on the proposed architecture.

A campus-wide view of the smart classrooms based on the proposed architecture is illustrated in Figure 18. As the proposed supporting measures, all smart classrooms, including the virtual smart classroom, use identical private network configurations. Devices in layer 1, which are responsible for the same functions, are having identical configurations too. Therefore, devices configured and tested in the virtual smart classroom can be replacement devices for any smart classroom in this architecture. As mentioned in Section 2.3, the only network configuration for device control network differs from classroom to classroom is the external IP address of the NAT gateway for each classroom.

\section{Conclusions}

This work is the result of finding a solution for building smart classrooms in university campuses. Studies related to smart classroom are reviewed and important factors, in terms of technology and education for smart classrooms were found in some of the studies we have reviewed. However, a campus-wide smart classroom construction solution cannot be found. Therefore, we design and propose our own smart classroom architecture for building and maintaining smart classrooms at the university campus in this work.

In Section 1, the concept of the smart campus is discussed and the works related to smart campus definitions, such as References [1-6], are reviewed. In the subsection of background and related works, the relationship between learning and environment factors are discussed in References $[8-13,15,16]$, including seating arrangement, and environmental factors, such as $\mathrm{CO}_{2}$ levels and temperature, which are related to teaching and learning quality. Previous works related to smart classroom technology issues were also reviewed, and models and architectures to address particular technical issues were proposed or discussed in Reference [18-23]. Some technology related features important to smart classrooms are discussed in Reference [24-31]. Studies related to solving technical issues or to use technology to improve classroom activities, such as Referenence [32-35], were also reviewed. References of the technologies used in this work, such as Raspberry Pi, Python, Flask, PHP, MariaDB, 
RFID, RS232, and RS485 can be found in References [7,37,38,48-50,52-54], and recent works related to Flask, such as References [39-47], were also reviewed. In Reference [36], PI-SCLE was proposed for understanding students' preferences toward the smart classroom. Important factors of smart classrooms can also be found in Reference [36]. Some studies related to context-aware and smart classroom were also reviewed, such as References [55-57]. Works related to energy efficiency and energy saving issues, such as Reference [58-69], were reviewed. In Reference [71-78], topics such as IoT, Fog, and Cloud computing, which are important to this study, were discussed. At the end of Section 1-Section 1.1.6-recent works related to platforms and frameworks for smart campuses, such as References [79-84], were also ereviewed.

Although a suitable solution for building smart classrooms in university campuss was not found in previous studies, important features related to smart classrooms, context awareness, and energy savings discussed in the previous works are still significant for designing our proposed architecture.

The contribution of this work is that the proposed architecture is based on our study and MCU Smart Classroom project. The architecture consists of a smart classroom prototype, a technology integration model, and supporting measures for smart classroom operation. The smart classroom prototype includes import classroom features based on the reviewed studies. The technology integration model is novel and is suitable for massively constructing smart classrooms in university campuses. As a result, the way of implementing the proposed architecture is detailed, illustrated and explained with examples. Raspberry Pi was used as a key role in the proposed technology integration model. The demonstration shows that Raspberry Pi is suitable for building context-aware energy saving application for smart campus.

Although a feasible architecture was proposed in this work with examples for implantation, mechanisms such as authentication and authorization were not defined in this architecture. Details for data exchange in smart classroom application layers were not defined either. The security rules and layer 4 data exchange scheme for this architecture are suitable topics for future works.

Author Contributions: Conceptualization, J.-Y.S., and L.-S.H.; methodology, L.-S.H.; software, L.-S.H.; writing-original draft preparation, L.-S.H.; writing-review and editing, L.-S.H. and T.-L.P.; visualization, L.-S.H.; Project administration, T.-L.P.; Resources, J.-Y.S. Supervision, T.-L.P.

Funding: This research received no external funding.

Acknowledgments: This work is inspired by the process of constructing smart classrooms and solving problems for supporting daily smart classroom operations at Ming Chuan University in Taiwan. The authors thank Chuan Lee, the president of Ming Chuan University, for initiating the MCU Smart Classroom project, which is a subproject of the MCU Smart Campus Plan, and giving goals and resources for campus-wide smart classroom construction and operation. The authors also thank Jeanne Lee, the associate dean of the School of Design of Ming Chuan University, for the exterior and interior design of all smart classrooms in the MCU Smart Classroom Project.

Conflicts of Interest: The authors declare no conflict of interest.

\section{Appendix A}

Table A1. Connections between controlled devices and Raspberry Pi boards in layer 1.

\begin{tabular}{|c|c|c|}
\hline Device & L1 Device Control Path & Controller \\
\hline Projector & {$[$ Projector][RS232] $===[$ RS232][Adapter][USB] $===[$ USB][RPi] } & RPi-01 \\
\hline Screen & {$[$ Motor Unit][RS232] $===[$ RS232][Adapter][USB $]===[\mathrm{USB}][\mathrm{RP} i]$} & $\mathrm{RPi}-01$ \\
\hline Light 01 & {$[$ Light $][110 \mathrm{~V}]===[110 \mathrm{~V}][$ Relay Mod $][3.3 \mathrm{~V}]===[\mathrm{GPIO}][\mathrm{RPi}]$} & RPi-01 \\
\hline Light 02 & {$[$ Light $][110 \mathrm{~V}]===[110 \mathrm{~V}][$ Relay Mod $][3.3 \mathrm{~V}]===[\mathrm{GPIO}][\mathrm{RPi}]$} & RPi-01 \\
\hline Light 03 & {$[$ Light] $[110 \mathrm{~V}]===[110 \mathrm{~V}][$ Relay Mod][3.3V $]===[\mathrm{GPIO}][\mathrm{RPi}]$} & RPi-01 \\
\hline Light 04 & {$[$ Light $][110 \mathrm{~V}]===[110 \mathrm{~V}][$ Relay Mod $][3.3 \mathrm{~V}]===[\mathrm{GPIO}][\mathrm{RPi}]$} & $\mathrm{RPi}-01$ \\
\hline Inter. Board & {$[$ Inter. Board $][110 \mathrm{~V}]===[110 \mathrm{~V}][$ Relay Mod $][\mathrm{TCP}]===[\mathrm{TCP}][\mathrm{RPi}]$} & RPi-02 \\
\hline Temp. Sensor & {$[$ Sensor $][R S 485]==[$ RS485][Serial Gateway $][$ ModBus $]===[$ ModBus $][$ RPi $]$} & RPi-02 \\
\hline $\mathrm{CO} 2$ Sensor & {$[$ Sensor] $[$ RS485] $==[$ RS485][Serial Gateway $][$ ModBus $]===[$ ModBus $][$ RPi $]$} & $\mathrm{RPi}-02$ \\
\hline Fan & {$[$ Fan $][110 \mathrm{~V}]===[110 \mathrm{~V}][$ Relay Mod $][\mathrm{TCP}]===[\mathrm{TCP}][\mathrm{RP} \mathrm{i}]$} & RPi-03 \\
\hline Air Con. & [Air Con] $[$ RS485] $==[$ RS485][Serial Gateway][ModBus $]===[$ ModBus] $[$ RPi $]$ & RPi-03 \\
\hline Door & {$[\mathrm{EM}$ Lock $][110 \mathrm{~V}]===[110 \mathrm{~V}][$ Relay Mod $][3.3 \mathrm{~V}]===[\mathrm{GPIO}][\mathrm{RPi}]$} & RPi-03 \\
\hline RFID Reader & {$[$ RFID Reader][USB] $==>[\mathrm{USB}][\mathrm{RPi}]$} & $\mathrm{RPi}-03$ \\
\hline
\end{tabular}


Table A2. Mappings of layer 1 device actions to the corresponding layer 2 basic operations.

\begin{tabular}{cccc}
\hline Device & L1 Action & Controller & L2 Basic Operation \\
\hline Projector & Power on & RPi-01 & http://192.168.50.2:5000/projector/on \\
Projector & Power off & RPi-01 & http://192.168.50.2:5000/projector/off \\
Screen & Scroll up & RPi-01 & http://192.168.50.2:5000/screen/up \\
Screen & Scroll down & RPi-01 & http://192.168.50.2:5000/screen/down \\
Light 01 & Power on & RPi-01 & http://192.168.50.2:5000/light/01/on \\
Light 01 & Power off & RPi-01 & http://192.168.50.2:5000/light/01/off \\
Light 02 & Power on & RPi-01 & http://192.168.50.2:5000/light/02/on \\
Light 02 & Power off & RPi-01 & http://192.168.50.2:5000/light/02/off \\
Light 03 & Power on & RPi-01 & http://192.168.50.2:5000/light/03/on \\
Light 03 & Power off & RPi-01 & http://192.168.50.2:5000/light/03/off \\
Light 04 & Power on & RPi-01 & http://192.168.50.2:5000/light/04/on \\
Light 04 & Power off & RPi-01 & http://192.168.50.2:5000/light/05/off \\
Inter. Board & Power on & RPi-02 & http://192.168.50.3:5000/board/on \\
Inter. Board & Power off & RPi-02 & http://192.168.50.3:5000/board/off \\
Temp. Sensor & Get Temp. & RPi-02 & http://192.168.50.3:5000/temp/get \\
CO Sensor & Get CO level & RPi-02 & http://192.168.50.3:5000/co2/get \\
Fan & Power on & RPi-03 & http://192.168.50.4:5000/fan/on \\
Fan & Power off & RPi-03 & http://192.168.50.4:5000/fan/off \\
Air Con. & Power on & RPi-03 & http://192.168.50.4:5000/aircon/on \\
Air Con. & Power off & RPi-03 & http://192.168.50.4:5000/aircon/off \\
Door & Lock & RPi-03 & http://192.168.50.4:5000/door/lock \\
Door & Unlock & RPi-03 & http://192.168.50.4:5000/door/unlock \\
\hline & &
\end{tabular}

Table A3. Port redirection settings on the smart classroom NAT gateway.

\begin{tabular}{ccccccc}
\hline Room ID & Controller & Ext. IP & Ext. Port & Dir. & Private IP & Service Port \\
\hline H204 & RPi-01 & 10.0 .0 .1 & 5001 & $\rightarrow$ & 192.168 .50 .2 & 5000 \\
H204 & RPi-02 & 10.0 .0 .1 & 5002 & $\rightarrow$ & 192.168 .50 .3 & 5000 \\
H204 & RPi-03 & 10.0 .0 .1 & 5003 & $\rightarrow$ & 192.168 .50 .4 & 5000 \\
\hline
\end{tabular}

Table A4. Layer 2 basic operations registered on the central web server.

\begin{tabular}{ccccc}
\hline Room ID & Device & L1 Action & Controller & L2 Basic Operation \\
\hline H204 & Projector & Power on & RPi-01 & http://10.0.0.1:5001/projector/on \\
H204 & Projector & Power off & RPi-01 & http://10.0.0.1:5001/projector/off \\
H204 & Screen & Scroll up & RPi-01 & http://10.0.0.1:5001/screen/up \\
H204 & Screen & Scroll down & RPi-01 & http://10.0.0.1:5001/screen/down \\
H204 & Light 01 & Power on & RPi-01 & http://10.0.0.1:5001/light/01/on \\
H204 & Light 01 & Power off & RPi-01 & http://10.0.0.1:5001/light/01/off \\
H204 & Light 02 & Power on & RPi-01 & http://10.0.0.1:5001/light/02/on \\
H204 & Light 02 & Power off & RPi-01 & http://10.0.0.1:5001/light/02/off \\
H204 & Light 03 & Power on & RPi-01 & http://10.0.0.1:5001/light/03/on \\
H204 & Light 03 & Power off & RPi-01 & http://10.0.0.1:5001/light/03/off \\
H204 & Light 04 & Power on & RPi-01 & http://10.0.0.1:5001/light/04/on \\
H204 & Light 04 & Power off & RPi-01 & http://10.0.0.1:5001/light/05/off \\
H204 & Inter. Board & Power on & RPi-02 & http://10.0.0.1:5002/board/on \\
H204 & Inter. Board & Power off & RPi-02 & http://10.0.0.1:5002/board/off \\
H204 & Temp. Sensor & Get Temp. & RPi-02 & http://10.0.0.1:5002/temp/get \\
H204 & CO Sensor & Get CO 2 level & RPi-02 & http://10.0.0.1:5002/co2/get \\
H204 & Fan & Power on & RPi-03 & http://10.0.0.1:5003/fan/on \\
H204 & Fan & Power off & RPi-03 & http://10.0.0.1:5003/fan/off \\
H204 & Air Con. & Power on & RPi-03 & http://10.0.0.1:5003/aircon/on \\
H204 & Air Con. & Power off & RPi-03 & http://10.0.0.1:5003/aircon/off \\
H204 & Door & Lock & RPi-03 & http://10.0.0.1:5003/door/lock \\
H204 & Door & Unlock & RPi-03 & http://10.0.0.1:5003/door/unlock \\
\hline
\end{tabular}

\footnotetext{
$1 \overline{\{\text { Room ID, Device, L1 Action\} represents a unique layer } 2 \text { operation in a specific smart classroom }}$
} 
Table A5. Layer 3 Combo operations configured on the central web server.

\begin{tabular}{|c|c|c|c|}
\hline Room ID & L3 OP ID & Combo Operation & L3 Operation and the Corresponding L2 Operations \\
\hline H204 & C0001 & Turn On Everything & $\begin{array}{c}\text { Layer 3: https://172.16.1.1/combo/H204/C001 } \\
\text { Layer 2: } \\
\text { Projector on: }\{\mathrm{H} 204, \text { Projector,Power on }\} \\
\text { Screen down: }\{\mathrm{H} 204, \text { Screen,Scroll down }\} \\
\text { Light } 01 \text { on: }\{\mathrm{H} 204, \text { Light } 01, \text { Power on }\} \\
\text { Light } 02 \text { on: }\{\mathrm{H} 204, \text { Light } 02, \text { Power on }\} \\
\text { Light } 03 \text { on: }\{\mathrm{H} 204, \text { Light } 03, \text { Power on }\} \\
\text { Light } 04 \text { on: }\{\mathrm{H} 204, \text { Light } 04, \text { Power on }\} \\
\text { Interactive board on: }\{\mathrm{H} 204, \text { Inter. Board,Power on }\} \\
\text { Air Con on: }\{\mathrm{H} 204, \text { Air Con,Power on }\} \\
\text { Fan on: }\{\mathrm{H} 204, \text { Fan,Power on }\}\end{array}$ \\
\hline H204 & $\mathrm{C} 0002$ & Use Projector & $\begin{array}{c}\text { Layer 3: https://172.16.1.1/combo/H204/C002 } \\
\text { Layer 2: } \\
\text { Projector on: }\{\mathrm{H} 204, \text { Projector,Power on }\} \\
\text { Screen down: }\{\mathrm{H} 204, \text { Screen,Scroll down }\} \\
\text { Light 01 off: }\{\mathrm{H} 204, \text { Light 01,Power off }\} \\
\text { Light 02 on: }\{\mathrm{H} 204, \text { Light 02,Power on }\} \\
\text { Light 03 on: }\{\mathrm{H} 204, \text { Light 03,Power on }\} \\
\text { Light 04 on: }\{\mathrm{H} 204, \text { Light 04,Power on }\} \\
\text { Interactive board off: }\{\mathrm{H} 204, \text { Inter. Board,Power off }\}\end{array}$ \\
\hline H204 & C0003 & Use Whiteboard & $\begin{array}{c}\text { Layer 3: https://172.16.1.1/combo/H204/C003 } \\
\text { Layer 2: } \\
\text { Projector off: }\{\mathrm{H} 204, \text { Projector,Power off }\} \\
\text { Screen up: }\{\mathrm{H} 204, \text { Screen,Scroll up }\} \\
\text { Light } 01 \text { on: }\{\mathrm{H} 204, \text { Light 01,Power on }\} \\
\text { Light } 02 \text { on: }\{\mathrm{H} 204, \text { Light } 02, \text { Power on }\} \\
\text { Light } 03 \text { on: }\{\mathrm{H} 204, \text { Light 03,Power on }\} \\
\text { Light 04 on: }\{\mathrm{H} 204, \text { Light } 04, \text { Power on }\} \\
\text { Interactive board off: }\{\mathrm{H} 204, \text { Inter. Board,Power off }\}\end{array}$ \\
\hline H204 & $\mathrm{C} 0004$ & $\begin{array}{l}\text { Use Interactive Board } \\
\text { without Projector }\end{array}$ & $\begin{array}{c}\text { Layer 3: https://172.16.1.1/combo/H204/C004 } \\
\text { Layer 2: } \\
\text { Projector off: }\{\text { H204, Projector, Power off }\} \\
\text { Screen up: }\{\mathrm{H} 204, \text { Screen,Scroll up }\} \\
\text { Light } 01 \text { on: }\{\mathrm{H} 204, \text { Light 01,Power on }\} \\
\text { Light } 02 \text { off: }\{\mathrm{H} 204, \text { Light 02,Power off }\} \\
\text { Light } 03 \text { on: }\{\mathrm{H} 204, \text { Light } 03, \text { Power on }\} \\
\text { Light } 04 \text { on: }\{\mathrm{H} 204, \text { Light } 04, \text { Power on }\} \\
\text { Interactive board on: }\{\mathrm{H} 204, \text { Inter. Board,Power on }\}\end{array}$ \\
\hline H204 & C0005 & Turn Off Everything & $\begin{array}{c}\text { Layer 3: https://172.16.1.1/combo/H204/C005 } \\
\text { Layer 2: } \\
\text { Projector off: }\{\mathrm{H} 204 \text { Projector, Power off }\} \\
\text { Screen off: }\{\mathrm{H} 204, \text { Screen,Scroll up }\} \\
\text { Light } 01 \text { off: }\{\mathrm{H} 204, \text { Light } 01, \text { Power off }\} \\
\text { Light } 02 \text { off: }\{\mathrm{H} 204, \text { Light } 02, \text { Power off }\} \\
\text { Light } 03 \text { off: }\{\mathrm{H} 204, \text { Light } 03, \text { Power off }\} \\
\text { Light } 04 \text { off: }\{\mathrm{H} 204, \text { Light } 04, \text { Power off }\} \\
\text { Interactive board off: }\{\mathrm{H} 204, \text { Inter. Board,Power off }\} \\
\text { Air Con off }\{\mathrm{H} 204 \text { Air Con, Power off }\} \\
\text { Fan off: }\{\mathrm{H} 204, \text { Fan, Power off }\}\end{array}$ \\
\hline
\end{tabular}

\section{References}

1. Muhamad, W.; Kurniawan, N.B.; Suhardi; Yazid, S. Smart campus features, technologies, and applications: A systematic literature review. In Proceedings of the 2017 International Conference on Information Technology Systems and Innovation (ICITSI), Bandung, Indonesia, 23-24 October 2017; pp. 384-391.

2. Jisc Home Page. Available online: https://www.jisc.ac.uk/ (accessed on 24 April 2019).

3. Guide to the Intelligent Campus. Available online: https://repository.jisc.ac.uk/6882/1/Intelligent_Campus_ Guide.pdf (accessed on 24 April 2019). 
4. Malatji, E.M. The Development of a Smart Campus-African Universities Point of View. In Proceedings of the 2017 8th International Renewable Energy Congress (IREC), Amman, Jordan, 21-23 March 2017; pp. 1-5.

5. John, T.M.; Ucheaga, E.G.; Badejo, J.A.; Atayero, A.A. A Framework for a Smart Campus: A Case of Covenant University. In Proceedings of the 2017 International Conference on Computational Science and Computational Intelligence (CSCI), Las Vegas, NV, USA, 14-16 December 2017; pp. 1371-1376.

6. Alghamdi, A.; Shetty, S. Survey Toward a Smart Campus Using the Internet of Things. In Proceedings of the 2016 IEEE 4th International Conference on Future Internet of Things and Cloud (FiCloud), Vienna, Austria, 22-24 August 2016; pp. 235-239.

7. Raspberry Pi Home Page. Available online: https://www.raspberrypi.org/ (accessed on 23 November 2018).

8. Uzelac, A.; Gligoric, N.; Krco, S. System for recognizing lecture quality based on analysis of physical parameters. Telemat. Inform. 2018, 35, 579-594. [CrossRef]

9. Uzelac, A.; Gligoric, N.; Krco, S. A comprehensive study of parameters in physical environment that impact students' focus during lecture using Internet of Things. Comput. Hum. Behav. 2015, 53, 427-434. [CrossRef]

10. Van De Bogart, W.; Wichadee, S. Students' Perceived Effectiveness of Educational Technologies and Motivation in Smart Classroom. Tem J.-Technol. Educ. Manag. Inform. 2016, 5, 566-574. [CrossRef]

11. Park, E.L.; Choi, B.K. Transformation of classroom spaces: Traditional versus active learning classroom in colleges. High. Educ. 2014, 68, 749-771. [CrossRef]

12. Sardinha, L.; Almeida, A.M.P.; Pedro, N. Bridging approaches: Classroom Physical Space as a learning ecosystem. Interact. Des. Archit. 2017, 35, 56-74.

13. Future Classroom Lab. Available online: http://www.eun.org/professional-development/future-classroom-lab (accessed on 20 December 2018).

14. European Schoolnet Home Page. Available online: http://www.eun.org/home (accessed on 21 December 2018).

15. Learning Zones of the Future Classroom Lab. Available online: http://fcl.eun.org/documents/10180/13526/ FCL+learning+zones+Dec+2016/a091a761-7a63-443e-afe0-d1870e430686 (accessed on 21 December 2018).

16. Dai, S.L. ARS Interactive Teaching Mode for Financial Accounting Course based on Smart Classroom. Int. J. Emerg. Technol. Learn. 2019, 14, 38-50. [CrossRef]

17. Xie, W.; Shi, Y.; Xu, G.; Xie, D. Smart Classroom-An Intelligent Environment for Tele-education. In Proceedings of the Advances in Multimedia Information Processing-PCM 2001, Beijing, China, 24-26 October 2001; pp. 662-668.

18. The Open Agent Architecture. Available online: http://www.ai.sri.com/ \{\}oaa/ (accessed on 14 October 2018).

19. Mao, Y.; Xie, W.; Shi, Y.; Xu, G.; Xiang, X. Building the Software Infrastructure for Smart Classroom: From Open Agent Architecture (OAA) to Smart Platform. In Proceedings of the Advances in Multimedia Information Processing-PCM 2002, Hsinchu, Taiwan, 16-18 December 2002; pp. 526-533.

20. Snow, C.; Pullen, J.M.; McAndrews, P. Network Education Ware: An open-source web-based system for synchronous distance education. IEEE Trans. Educ. 2005, 48, 705-712. [CrossRef]

21. The Network Education Ware Project. Available online: https://netlab.gmu.edu/NEW/ (accessed on 13 December 2018).

22. Qin, W.J.; Suo, Y.; Shi, Y.C. CAMPS: A middleware for providing context-aware services for Smart Space. In Advances in Grid and Pervasive Computing, Proceedings; Chung, Y.C., Moreira, J.E., Eds.; Springer: Berlin/Heidelberg, Germany, 2006; Volume 3947, pp. 644-653.

23. Suo, Y.; Miyata, N.; Morikawa, H.; Ishida, T.; Shi, Y.C. Open Smart Classroom: Extensible and Scalable Learning System in Smart Space Using Web Service Technology. IEEE Trans. Knowl. Data Eng. 2009, 21, 814-828. [CrossRef]

24. Shi, Y.C.; Xie, W.K.; Xu, G.Y.; Shi, R.; Chen, E.; Mao, Y.H.; Liu, F. The smart classroom: Merging technologies for seamless tele-education. IEEE Pervasive Comput. 2003, 2, 47-55. [CrossRef]

25. Shen, C.W.; Wu, Y.C.J.; Lee, T.C. Developing a NFC-equipped smart classroom: Effects on attitudes toward computer science. Comput. Hum. Behav. 2014, 30, 731-738. [CrossRef]

26. Al-Qirim, N. Determinants of interactive white board success in teaching in higher education institutions. Comput. Educ. 2011, 56, 827-838. [CrossRef]

27. Tissenbaum, M.; Lui, M.; Slotta, J.D. Co-Designing Collaborative Smart Classroom Curriculum for Secondary School Science. J. Univers. Comput. Sci. 2012, 18, 327-352.

28. Yang, J.F.; Yu, H.J.; Gong, C.H.; Chen, N.S. Students' Perceptions and Behaviour in Technology-Rich Classroom and Multi-Media Classroom. Eurasia J. Math. Sci. Technol. Educ. 2017, 13, 621-647. [CrossRef] 
29. Teo, T. An initial development and validation of a Digital Natives Assessment Scale (DNAS). Comput. Educ. 2013, 67, 51-57. [CrossRef]

30. Gul, S.; Asif, M.; Ahmad, S.; Yasir, M.; Majid, M.; Malik, M.S.A. A Survey on Role of Internet of Things in Education. Int. J. Comput. Sci. Netw. Secur. 2017, 17, 159-165.

31. Chamba-Eras, L.; Aguilar, J. Augmented Reality in a Smart Classroom-Case Study: SaCI. IEEE Revista Iberoamericana De Tecnologias Del Aprendizaje IEEE Rita 2017, 12, 165-172. [CrossRef]

32. Kim, Y.; Soyata, T.; Behnagh, R. Towards Emotionally Aware AI Smart Classroom: Current Issues and Directions for Engineering and Education. IEEE Access 2018, 6, 5308-5331. [CrossRef]

33. Aguilar, J.; Sanchez, M.; Cordero, J.; Valdiviezo-Diaz, P.; Barba-Guaman, L.; Chamba-Eras, L. Learning analytics tasks as services in smart classrooms. Univers. Access Inf. Soc. 2018, 17, 693-709. [CrossRef]

34. Gu, H.L.; Shi, Y.C.; Xu, G.Y.; Chen, Y. A core model supporting location-aware computing in smart classroom. In Advances in Web-Based Learning-ICWL 2005; Lau, R.W.H., Li, Q., Cheung, R., Liu, W., Eds.; Springer: Berlin/Heidelberg, Germany, 2005; Volume 3583, pp. 1-13.

35. Pirahandeh, M.; Kim, D.H. Energy-aware and intelligent storage features for multimedia devices in smart classroom. Multimed. Tools Appl. 2017, 76, 1139-1157. [CrossRef]

36. MacLeod, J.; Yang, H.H.; Zhu, S.; Li, Y.H. Understanding students' preferences toward the smart classroom learning environment: Development and validation of an instrument. Comput. Educ. 2018, 122, 80-91. [CrossRef]

37. Python Home Page. Available online: https://www.python.org/ (accessed on 12 October 2018).

38. Flask microframework Home Page. Available online: http://flask.pocoo.org/ (accessed on 12 October 2018).

39. Parikh, V.; Keskar, M.; Dharia, D.; Gotmare, P. A Tourist Place Recommendation and Recognition System. In Proceedings of the 2018 Second International Conference on Inventive Communication and Computational Technologies (ICICCT), Coimbatore, India, 20-21 April 2018; pp. 218-222.

40. Nepomuceno, T.; Carneiro, T.; Carneiro, T.; Korn, C.; Martin, A. A GUI-based Platform for Quickly Prototyping Server-side IoT Applications. In Proceedings of the Smart SysTech 2018; European Conference on Smart Objects, Systems and Technologies, Munich, Germany, 12-13 June 2018; pp. 1-9.

41. Kauling, D.; Mahmoud, Q.H. Sensorian Hub: An IFTTT-based platform for collecting and processing sensor data. In Proceedings of the 2017 14th IEEE Annual Consumer Communications \& Networking Conference (CCNC), Las Vegas, NV, USA, 8-11 January 2017; pp. 504-509.

42. Gharibi, G.; Alanazi, R.; Lee, Y. Automatic Hierarchical Clustering of Static Call Graphs for Program Comprehension. In Proceedings of the 2018 IEEE International Conference on Big Data (Big Data), Seattle, WA, USA, 10-13 December 2018; pp. 4016-4025.

43. Tiankaew, U.; Chunpongthong, P.; Mettanant, V. A Food Photography App with Image Recognition for Thai Food. In Proceedings of the 2018 Seventh ICT International Student Project Conference (ICT-ISPC), Nakhonpathom, Thailand, 11-13 July 2018; pp. 1-6.

44. Çelık, N.; Oğul, H. A web application for content based geographic image retrieval. In Proceedings of the 2017 25th Signal Processing and Communications Applications Conference (SIU), Antalya, Turkey, 15-18 May 2017; pp. 1-4.

45. Singh, S.; Kaushik, A.; Chitkara, S.S. Ubiquitously controlled personalized smartlock. In Proceedings of the 2017 International Conference on I-SMAC (IoT in Social, Mobile, Analytics and Cloud) (I-SMAC), Palladam, India, 10-11 February 2017; pp. 686-691.

46. Patil, S.M.; Vijayalashmi, M.; Tapaskar, R. IoT based solar energy monitoring system. In Proceedings of the 2017 International Conference on Energy, Communication, Data Analytics and Soft Computing (ICECDS), Chennai, India, 1-2 August 2017; pp. 1574-1579.

47. Vogel, P.; Klooster, T.; Andrikopoulos, V.; Lungu, M. A Low-Effort Analytics Platform for Visualizing Evolving Flask-Based Python Web Services. In Proceedings of the 2017 IEEE Working Conference on Software Visualization (VISSOFT), Shanghai, China, 18-19 September 2017; pp. 109-113.

48. PHP Home Page. Available online: https://www.php.net/ (accessed on 20 April 2019).

49. Programming Languages Used in Most Popular Websites. Available online: https://en.wikipedia.org/wiki/ Programming_languages_used_in_most_popular_websites (accessed on 22 April 2019).

50. MariaDB Home Page. Available online: https://mariadb.org/ (accessed on 22 April 2019).

51. MySQL Home Page. Available online: https://www.mysql.com/ (accessed on 22 April 2019). 
52. Mo, J.P.T.; Sheng, Q.Z.; Li, X.; Zeadally, S. RFID Infrastructure Design: A Case Study of Two Australian RFID Projects. IEEE Internet Comput. 2009, 13, 14-21. [CrossRef]

53. RS-485. Available online: https://en.wikipedia.org/wiki/RS-485 (accessed on 22 April 2019).

54. RS-232. Available online: https://en.wikipedia.org/wiki/RS-232 (accessed on 22 April 2019).

55. Li, X.; Feng, L.; Zhou, L.Z.; Shi, Y.C. Learning in an Ambient Intelligent World: Enabling Technologies and Practices. IEEE Trans. Knowl. Data Eng. 2009, 21, 910-924. [CrossRef]

56. Dutta, J.; Roy, S.; Chowdhury, C. Unified framework for IoT and smartphone based different smart city related applications. Microsyst. Technol.-Micro Nanosyst.-Inf. Storage Process. Syst. 2019, 25, 83-96. [CrossRef]

57. Arduino Home. Available online: https://www.arduino.cc/ (accessed on 8 December 2018).

58. Calvillo, C.F.; Sánchez-Miralles, A.; Villar, J. Energy management and planning in smart cities. Renew. Sustain. Energy Rev. 2016, 55, 273-287. [CrossRef]

59. Carli, R.; Dotoli, M.; Pellegrino, R. A Hierarchical Decision-Making Strategy for the Energy Management of Smart Cities. IEEE Trans. Autom. Sci. Eng. 2017, 14, 505-523. [CrossRef]

60. Blaauwbroek, N.; Nguyen, P.H.; Konsman, M.J.; Shi, H.; Kamphuis, R.I.G.; Kling, W.L. Decentralized Resource Allocation and Load Scheduling for Multicommodity Smart Energy Systems. IEEE Trans. Sustain. Energy 2015, 6, 1506-1514. [CrossRef]

61. Carli, R.; Dotoli, M. A decentralized resource allocation approach for sharing renewable energy among interconnected smart homes. In Proceedings of the 2015 54th IEEE Conference on Decision and Control (CDC), Osaka, Japan, 15-18 December 2015; pp. 5903-5908.

62. Brusco, G.; Burgio, A.; Menniti, D.; Pinnarelli, A.; Sorrentino, N. Energy Management System for an Energy District With Demand Response Availability. IEEE Trans. Smart Grid 2014, 5, 2385-2393. [CrossRef]

63. Carli, R.; Dotoli, M. Cooperative Distributed Control for the Energy Scheduling of Smart Homes with Shared Energy Storage and Renewable Energy Source. IFAC-PapersOnLine 2017, 50, 8867-8872. [CrossRef]

64. Figueiredo, J.; Sá da Costa, J. A SCADA system for energy management in intelligent buildings. Energy Build. 2012, 49, 85-98. [CrossRef]

65. Carli, R.; Dotoli, M. Energy scheduling of a smart home under nonlinear pricing. In Proceedings of the 53rd IEEE Conference on Decision and Control, Los Angeles, CA, USA, 15-17 December 2014; pp. 5648-5653.

66. Chiou, C.B.; Chiou, C.H.; Chu, C.M.; Lin, S.L. The study of energy-saving strategy for direct expansion air conditioning system. Energy Build. 2008, 40, 1660-1665. [CrossRef]

67. Chung, M.H.; Rhee, E.K. Potential opportunities for energy conservation in existing buildings on university campus: A field survey in Korea. Energy Build. 2014, 78, 176-182. [CrossRef]

68. Mahlia, T.M.I.; Razak, H.A.; Nursahida, M.A. Life cycle cost analysis and payback period of lighting retrofit at the University of Malaya. Renew. Sustain. Energy Rev. 2011, 15, 1125-1132. [CrossRef]

69. Motta Cabrera, D.F.; Zareipour, H. Data association mining for identifying lighting energy waste patterns in educational institutes. Energy Build. 2013, 62, 210-216. [CrossRef]

70. Ming Chuan University Official Website. Available online: https://web.mcu.edu.tw/en (accessed on 20 February 2019).

71. Overview of the Internet of Things. Available online: http://handle.itu.int/11.1002/1000/11559 (accessed on 18 April 2019).

72. Mell, P.; Grance, T. The NIST Definition of Cloud Computing; NIST, Ed.; NIST: Gaithersburg, MA, USA, 2011.

73. Gubbi, J.; Buyya, R.; Marusic, S.; Palaniswami, M. Internet of Things (IoT): A vision, architectural elements, and future directions. Future Gener. Comput. Syst. 2013, 29, 1645-1660. [CrossRef]

74. Lorga, M.; Feldman, L.; Barton, R.; Martin, M.J.; Goren, N.S.; Mahmoudi, C. Fog Computing Conceptual Model; NIST, Ed.; NIST: Gaithersburg, MA, USA, 2018.

75. Bonomi, F.; Milito, R.; Zhu, J.; Addepalli, S. Fog computing and its role in the internet of things. In Proceedings of the first edition of the MCC workshop on Mobile cloud computing, Helsinki, Finland, 17 August 2012; pp. 13-16.

76. Burt, J. Fog Computing Aims to Reduce Processing Burden of Cloud Systems. Available online: https://www. eweek.com/networking/fog-computing-aims-to-reduce-processing-burden-of-cloud-systems (accessed on 18 April 2019).

77. Rahmani, A.; Thanigaivelan, N.K.; Tuan Nguyen, G.; Granados, J.; Negash, B.; Liljeberg, P.; Tenhunen, H. Smart e-Health Gateway: Bringing intelligence to Internet-of-Things based ubiquitous healthcare systems. 
In Proceedings of the 2015 12th Annual IEEE Consumer Communications and Networking Conference (CCNC), 9-12 January 2015; pp. 826-834.

78. Rahmani, A.M.; Gia, T.N.; Negash, B.; Anzanpour, A.; Azimi, I.; Jiang, M.; Liljeberg, P. Exploiting smart e-Health gateways at the edge of healthcare Internet-of-Things: A fog computing approach. Future Gener. Comput. Syst. 2018, 78, 641-658. [CrossRef]

79. Hentschel, K.; Jacob, D.; Singer, J.; Chalmers, M. Supersensors: Raspberry Pi Devices for Smart Campus Infrastructure. In Proceedings of the 2016 IEEE 4th International Conference on Future Internet of Things and Cloud (FiCloud), Vienna, Austria, 22-24 August 2016; pp. 58-62.

80. Wang, Y.; Saez, B.; Szczechowicz, J.; Ruisi, J.; Kraft, T.; Toscano, S.; Vacco, Z.; Nicolas, K. A smart campus internet of things framework. In Proceedings of the 2017 IEEE 8th Annual Ubiquitous Computing, Electronics and Mobile Communication Conference (UEMCON), New York City, NY, USA, 19-21 October 2017; pp. 498-503.

81. Narendrakumar, T.; Pillai, A.S. Smart connected campus. In Proceedings of the 2017 International Conference on Intelligent Computing, Instrumentation and Control Technologies (ICICICT), Kannur, Kerala, India, 6-7 July 2017; pp. 1591-1596.

82. Haghi, A.; Burney, K.; Kidd, F.S.; Valiente, L.; Peng, Y. Fast-paced development of a smart campus IoT platform. In Proceedings of the 2017 Global Internet of Things Summit (GIoTS), Geneva, Switzerland, 6-9 June 2017; pp. 1-6.

83. Xu, X.; Li, D.; Sun, M.; Yang, S.; Yu, S.; Manogaran, G.; Mastorakis, G.; Mavromoustakis, C.X. Research on Key Technologies of Smart Campus Teaching Platform Based on 5G Network. IEEE Access 2019, 7, 20664-20675. [CrossRef]

84. Yang, A.; Li, S.; Ren, C.; Liu, H.; Han, Y.; Liu, L. Situational Awareness System in the Smart Campus. IEEE Access 2018, 6, 63976-63986. [CrossRef]

85. International Conference on Smart Campus and Exhibition, iCSC\&E. Available online: http://icsc.tku.edu.tw/ (accessed on 1 December 2018).

(C) 2019 by the authors. Licensee MDPI, Basel, Switzerland. This article is an open access article distributed under the terms and conditions of the Creative Commons Attribution (CC BY) license (http://creativecommons.org/licenses/by/4.0/). 